\title{
IDENTITY OF MODERN ARCHITECTURE IN HISTORICAL CITY ENVIRONMENTS
}

\author{
Raffaele Gambassi, Architect \\ Via Salceto 87, Poggibonsi,Siena, Italy \\ raffaele@architettogambassi.it
}

\section{Abstract}

The debate on the modern architectural project in the historical city is one of the most interesting subject in our society. Architecture represents the cultural imprint of an age and from the care of the cities and territories is possible to judge the quality of a govern. The historical buildings have created our magnificent urban landscapes, result of different visions of city during the passing of time. The feeling of respect for this heritage is a duty towards the previous generations and a teaching to express the sign of our time as they did in the past, without fears but with a great awareness of the importance to leave the imprints of our culture in the history. The paper considers the different approaches of modern architecture when it faces the historical environments and outlines interesting conclusions.

Key words: modern and historical architecture, architectural heritage, historic centre

\section{The concept of good living}

The concept of beauty transcends all of human history. It is found in every material and spiritual expression of human endeavor.

In Italian cities, the principle of beauty was joined to the theme of good governance and good living. This is the true of Siena in Middle Ages, where the awareness of the political significance of the beauty of the city is also explicit in institutional forms and regulations: the appointment of the "officers of beauty", the provisions for regularity of the road layouts and building facades, projects for the public green space "a bellezza et pro del comune et de li cittadini".

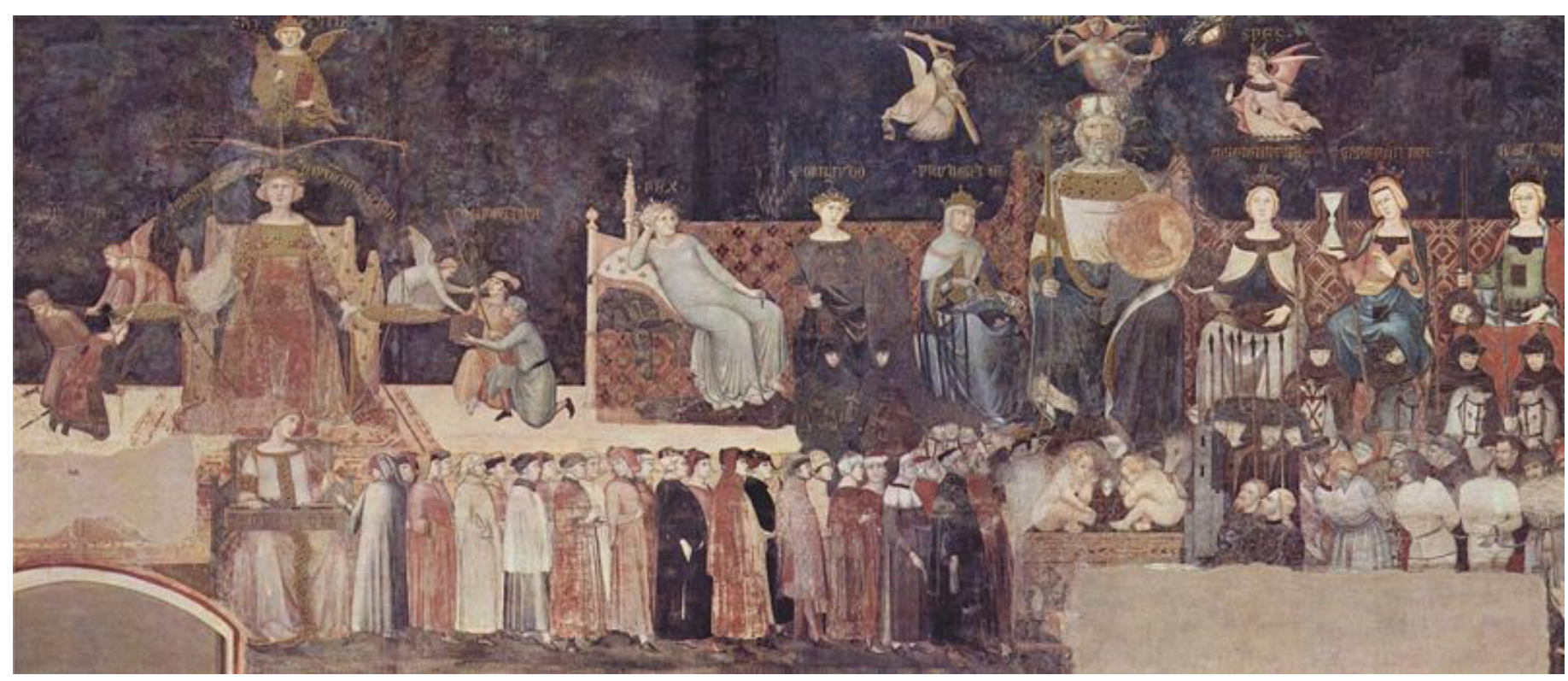

Photo 1. Allegoria degli Effetti del Buon Governo in città e campagna (Effects of good governance in city and countryside) - (Ambrogio Lorenzetti, Palazzo Pubblico, Siena, 1338) 


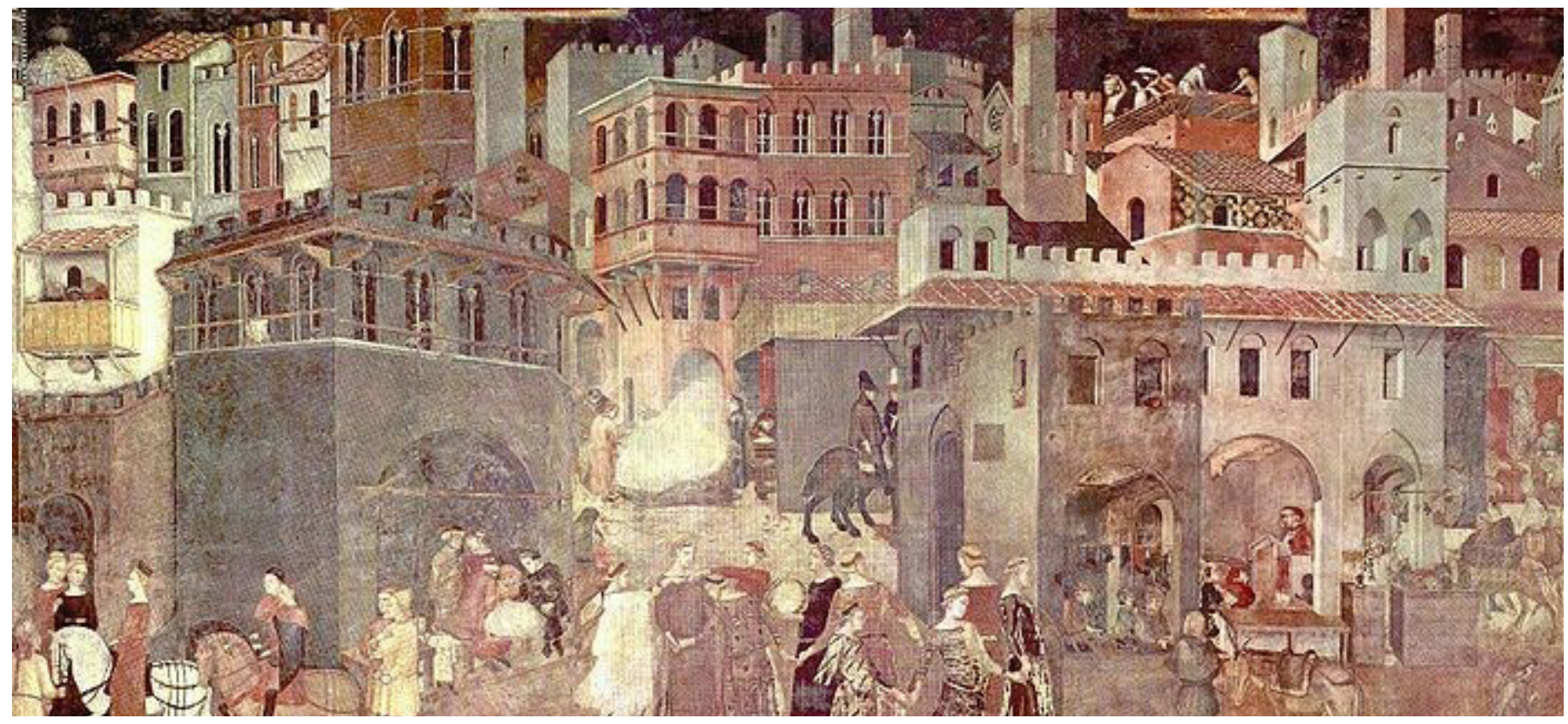

Photo 2. Effetti del Buon Governo in città (Effects of good governance effects in city) (Ambrogio Lorenzetti, Palazzo Pubblico, Siena, 1338)

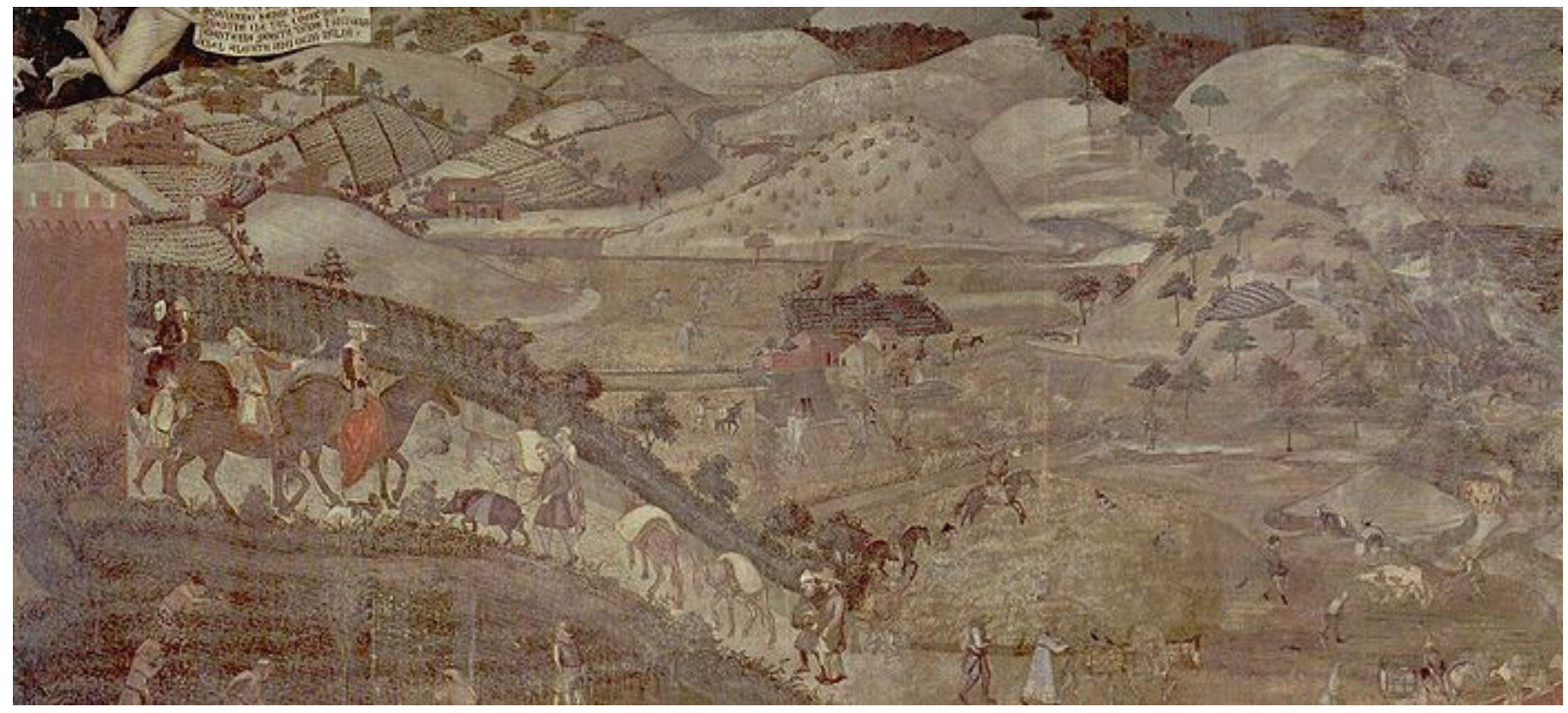

Photo 3. Effetti del Buon Governo in campagna (Effects of good governance in countryside) (Ambrogio Lorenzetti, Palazzo Pubblico, Siena, 1338)

"Whoever governs has to make the beauty of the city a priority. This causes delight because it enhances life for citizens and foreigners alike. It fosters prosperity and brings honour to the city and its inhabitants". Costituto Senese Law - 1309.

In medieval Siena the various commercial, artisan and intellectual activities flourished. The masons built new buildings in a growing city.

The fresco by Ambrogio Lorenzetti is considered the Magna Carta for the universal rights of the city. The mag- nificence and well being of the city extends to the countryside. The city is like an open entity and the countryside is used wisely and nature is respected.

The City of Good Living, therefore, must be beautiful, friendly, unified, consolidated and, capable to express the values of a community proud of itself and its history, and at the same time it must be ready to embrace the great challenges of innovation and development. This is a utopia that can be achieved even nowadays, where the management of the transformation processes creates the ability to deal with large 
and small problems: from the simple maintenance of a building to the creation of a new urban district, having a clear idea of the city and its citizens' needs. In large metropolitan areas this is no longer possible, because it is not possible to produce a clear synthesis of the many interests involved in defining a shared project in which the reasons for the economic and productivity growth will combine with the social values and culture of living and working together. Italian cities have tremendous potential to become the protagonists of that widespread prosperity that is measured by intangible indicators, such as the genius loci, the sense of belonging and the desire to live in a city as a home.

A city that wants to perpetuate in growth, its historical identity, but is also available to produce, through the project, new urban identity and more advanced opportunities for the lives of citizens. In short, there is still hope for the future of our cities. Or rather, for those small and medium-sized urban areas which represent a large part of our town and city environment.

In this context, an important factor is the "sense of belonging", which means a strong bond with its own history and memory and, at the same time, an extraordinary connection towards the future, because when the roots are strong the processes of transformation and development to be undertaken are clearer.

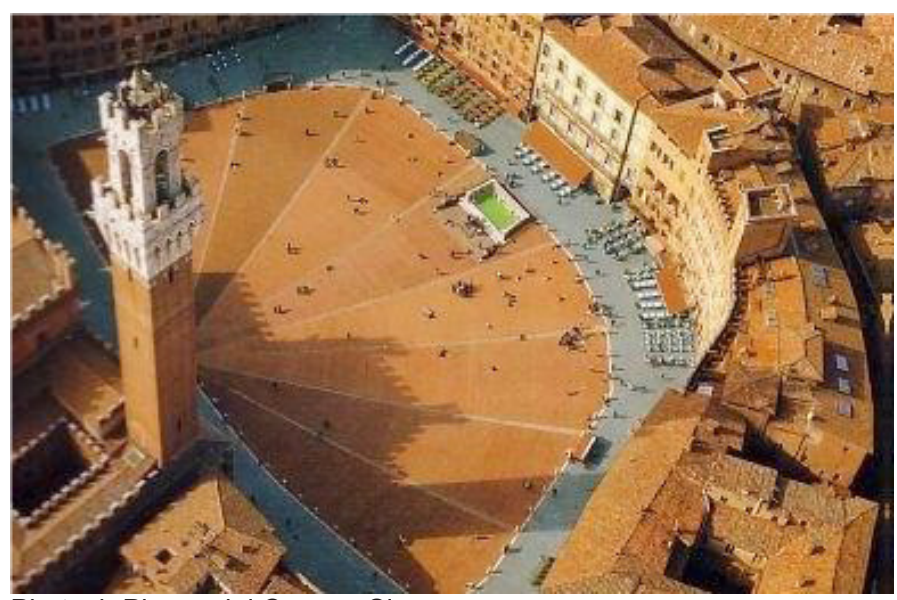

Photo 4. Piazza del Campo, Siena

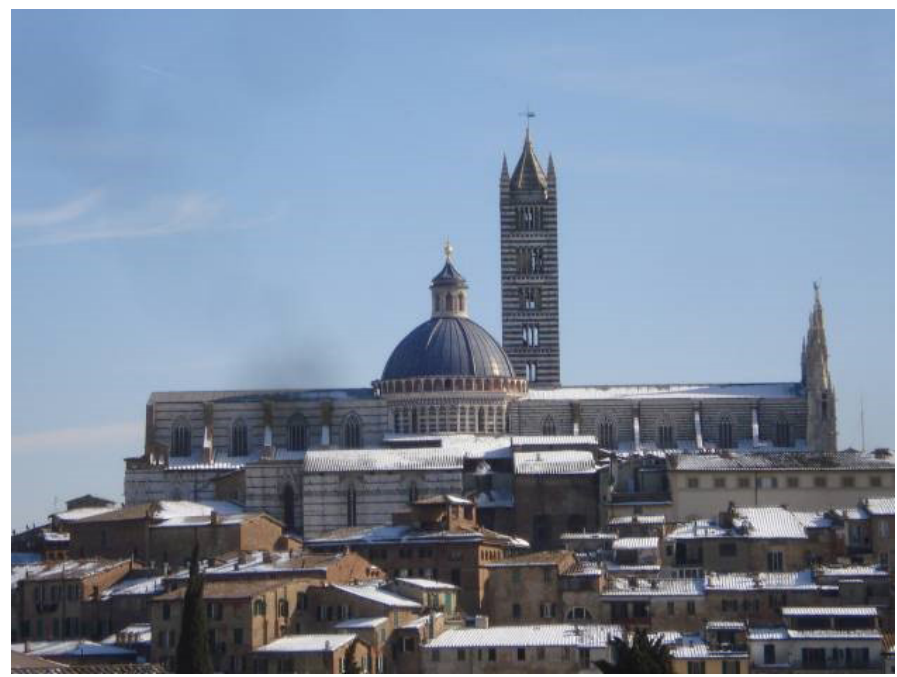

Photos 5-6. Views of Siena
If we think of the city as a common good, then there is also the ability to proceed united towards common objectives.

The city belongs to the community. Not surprisingly, the more alive and vital cities today are still the historical cities, those in which there is full agreement on the role of communal spaces as an integral part of the city. In short, the new city model remains that of the ancient city. A city in which the functions are integrated with each other and the public spaces are the benchmark for the entire urban layout.

\section{The city and the historic center}

In the traditional definition the city is defined as "centre of social life, significant both for the number of the inhabitants and for the ability to deliver multiple economic, political and cultural functions."

Today the city means the urban space where most of humanity lives following ongoing rhythms and dynamics: the city is the culture that must be constantly nourished and renewed, on pain of death and with it our civilization.

The city is the space of freedom and solidarity, the refuge and resource, poverty and wealth, and a place where humanity eats, works and thrives and it is a place of communication. The city is an archetype, because it is a collective aspiration as a vision to guide towards a sort of hoped-transcendence, through the harmony and the idea of "happy city." For this reason the city is and should be the utopia, representing the ideal of living together in freedom of progress.

In the current plethora of urban models, the city is the embodiment of a set of customs, traditions, attitudes and feelings, language, myth and art all at the same time. However, it is not always the same language: multiple cities exist within the same city.

Today's city, including its historic centre, is therefore different from all previous ones. One can see the mutations that have occurred and feel the pulse of the diverse societies which followed one another. Detecting the various expressive components as clear representations of a unique cultural orientation that capture an historical moment, is what makes up the culture of the city. This is due

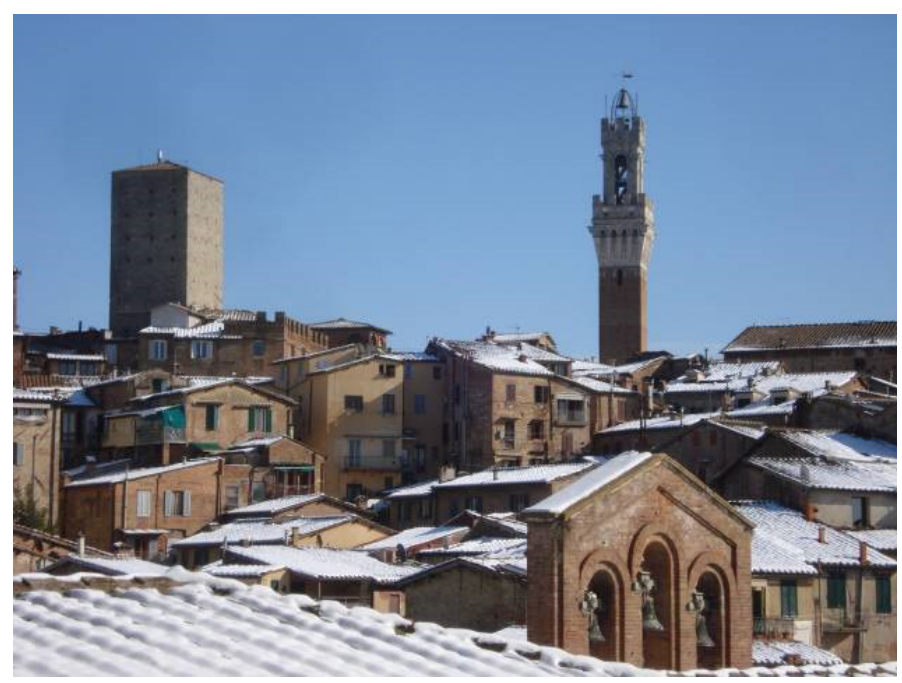


to the constant layering of successive languages, myths and arts brought about by the different stages of its evolution and its inhabitants.

Therein lies the true beauty of the historic centre.

The city of today is different from that of yesterday, and in turn different from the previous ones, in a succession without substantial continuity of stylistic concerns. The discontinuities that we can read in the city show that mutations occurred and then the stories of several cities that followed.

The city is never finished: it is actually a continuous spatial activity. The "culture of the city" is the identification of the various units of expression as obvious and sensible representations of a specific cultural orientation that characterizes an historic moment.

With awareness of its culture, the city itself becomes an active participant in its own use and to its representation. The city thus manifested its tradition and its trend line into the future and guides the community towards its progress.

NEED (protection, fairness, justice, utility) = FUNCTION = FORM = CITY

Architecture is one of the great parts of the city and its most significant aspect is the "monument". The monument is in fact the meeting point between the community and the aesthetic appearance of the city: the building, the sculpture, the park, the square, the ancient ruin, etc. They are the places where the community is confronted with a specific visual celebration. This is why the urban monument occupies very specific areas in the city, such as topographical or view reference but also a place of utility actions to receive, repair, protect, etc.: the monument is the ethical symbol of the city.

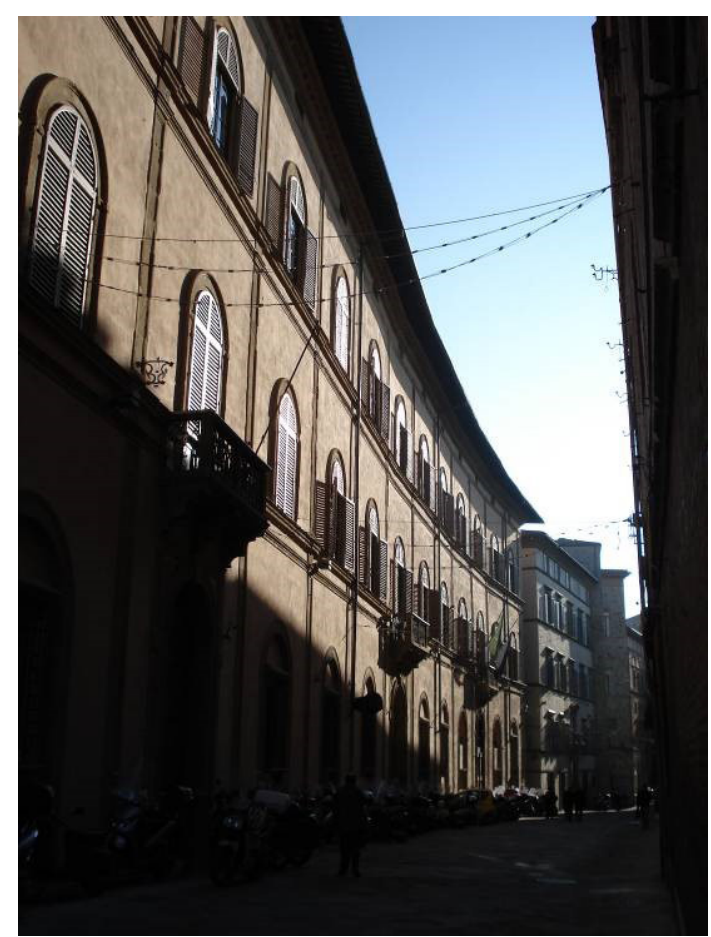

Photos 7-8. The historic centre of Siena
Let's look at the significance of the ancient centre (socalled "old town"). The current perception of the ancient centre is taken on an "icon of innocence" of the old space, pure original nucleus, but really it is a product of the city in itself, an invention that is only in our minds. The old centre is the urban childhood from which everyone tries to leave as soon as possible but it will continue to brighten its future steps. It is the childhood of each district, one known inch by inch, with all its secrets: it is a friendly space, cosy, protective: it is home.

At some point, however, it can become tight, oppressive, controlling and finally there is a desire to escape. Here it is that the centre becomes the ghetto, because the people living there are special, different from the rest of the city, and especially different from that of new parts; it's like a race apart, as old as the stones of the walls, not rich but noble, even though most of the time is spent in cramped and sunless cold spaces which are sometimes dirty. The historic centre becomes nostalgia for a certain image we have of the city and of our memories.

The old centre is the utopia of our past, an invention and thus a sublimation compared to what it actually was, and that is a dynamic sequence of cultural units that develop over time. It is therefore not a well-identified entity. Today the ancient centre is mythologized, has become the ideal to which to refer, to be entrusted with the sense of certainty, soundness, a social anchor to the place, in a city that often has lost its cultural unity; and in this myth as we exalt the perfection, the absolute ideal city. It 's a real utopian approach: the oldest town in reality was very different, often dominated by dirt, disorder in the changing structures and in a mixing of men, animals and plants, with strong social inequalities.

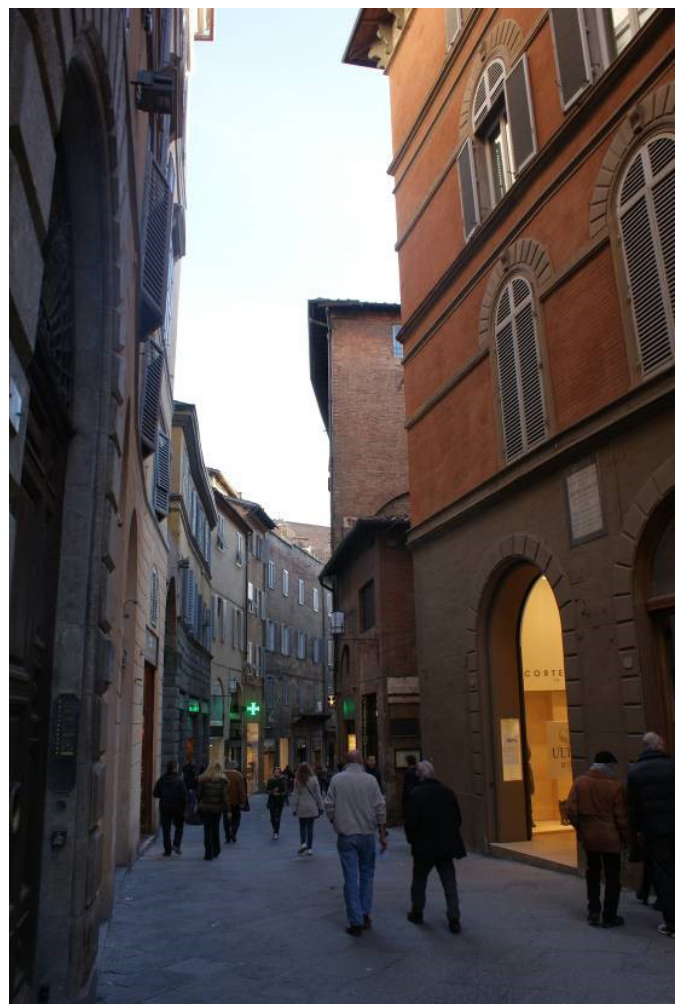


Objectively, the ancient centre is that part of the city that has become "a collective work of art", the result of the intervention of several generations, healing, restoring, reusing, thus manifesting their level of culture of the city.

The contemporary city as a whole is not yet on the other hand the history, because it has not yet woven its "myth"; it misses with what is the relationship with the acceptance, adoption, and the multiplicity of the changes introduced by the different generations, misunderstandings and ignorance.

So it is a great responsibility for the urban heir to be not an historian or a restorer but an artist who through the building should evoke the spirituality transmitted by the collective culture, and be able to complete the unfinished urban and territorial extant. Therefore, we can conclude that preserving an historic urban space does not mean to make it a museum but to establish the limits of its change.

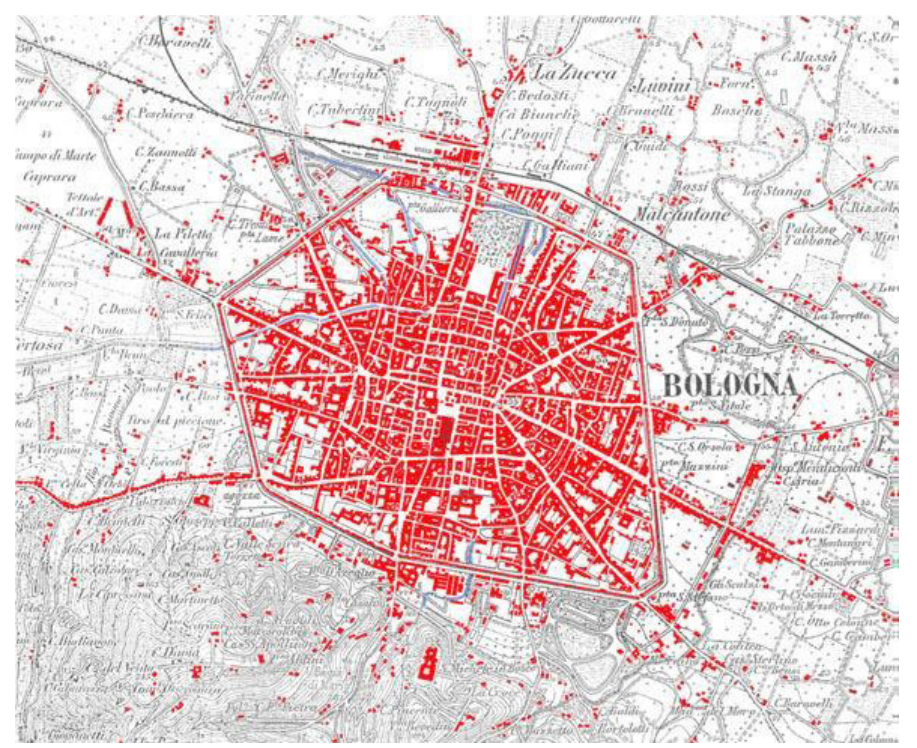

Photo 9. Bologna 1898

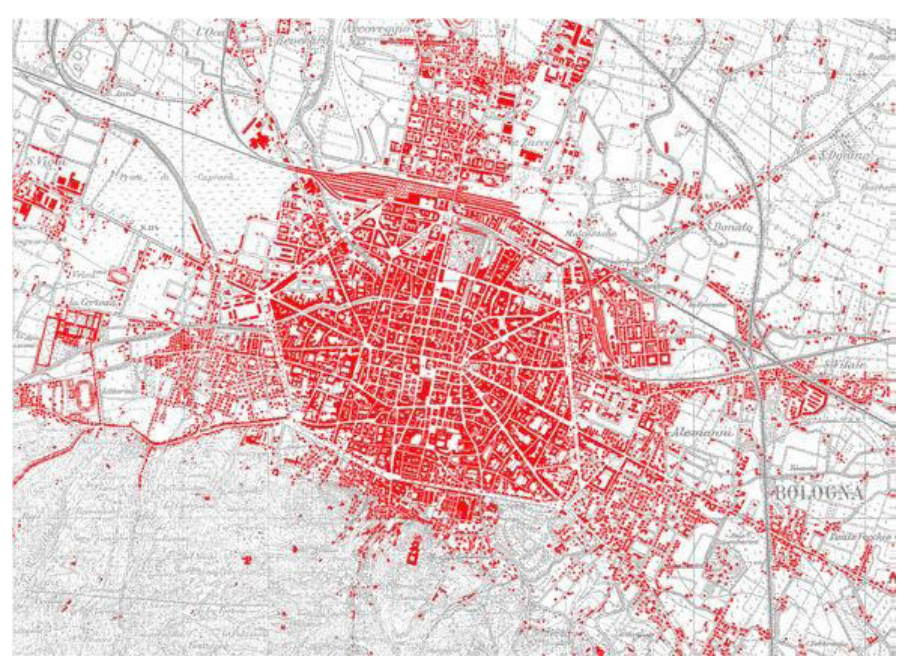

Photo 11. Bologna 1957

\section{Modern architecture and Historic cities}

The debate on the relationship between modern architecture and the historic city has been and is one of the constants in the Italian cultural scene. In a country like Italy the presence of a remarkable architectural heritage and urban history is undoubtedly a fundamental aspect for any form of design approach.

The first 4 images show the metamorphosis of the Forma Urbis of Bologna in the last century, since 1898, when it still had the four walls of the sixteenth century, a road structure and a skyline largely unchanged for centuries, until 1998, when the urbanized area went beyond the municipal borders to join with neighbouring villages and that highlights the transition from "the city" in the historical centre.

"Centre" of the suburbs that spread like wildfire, and that destroy the country. The loss of boundaries and form, due to the expansion around the historic city, has cancelled the sense of belonging to the city. The city has

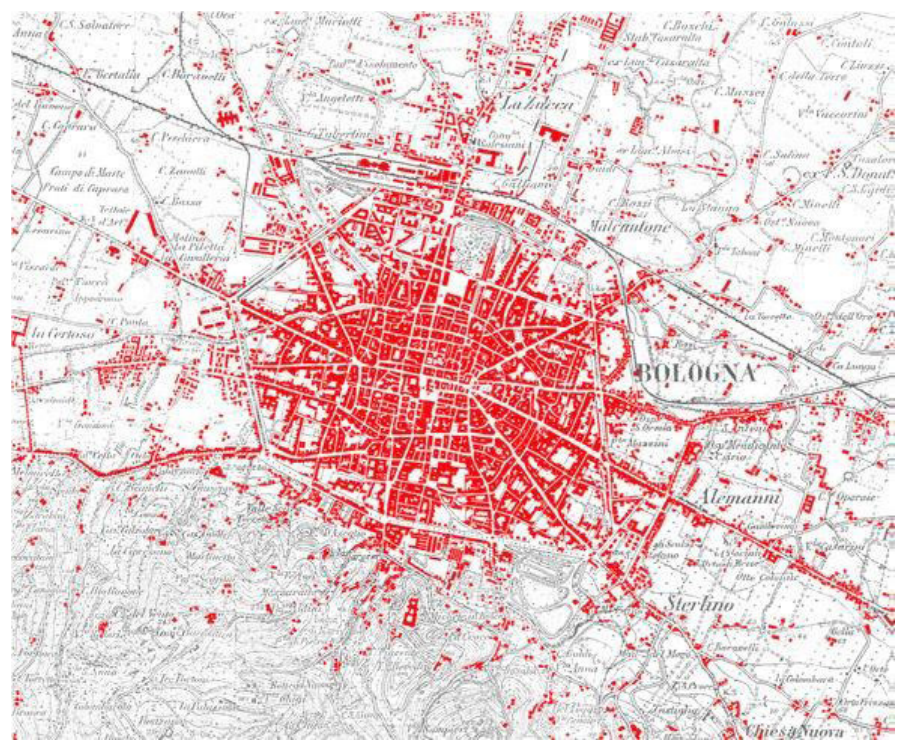

Photo 10. Bologna 1930

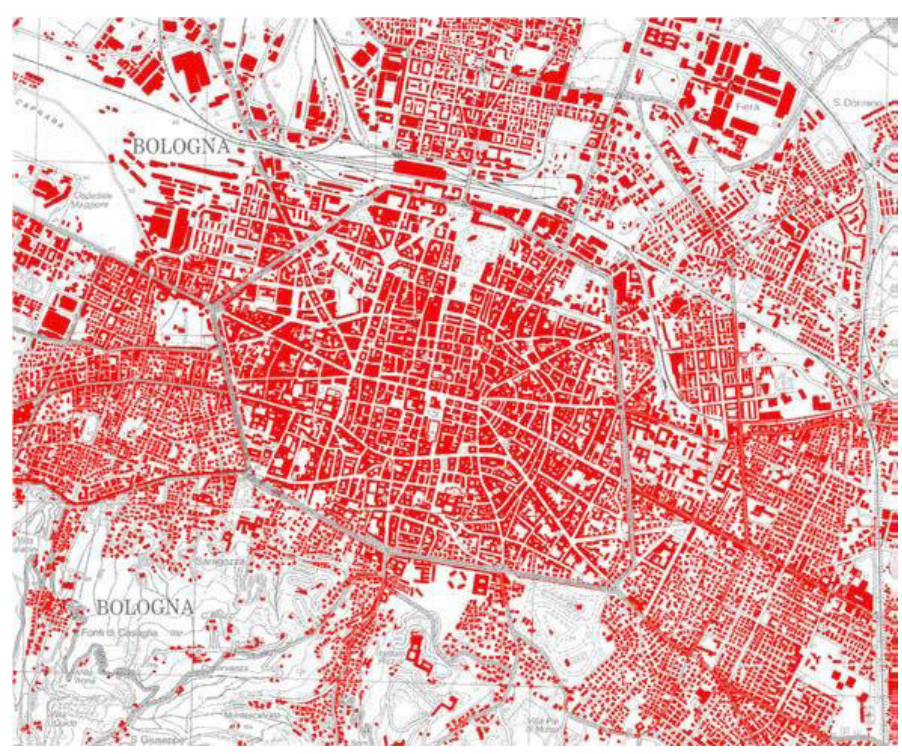

Photo 12. Bologna 1998 


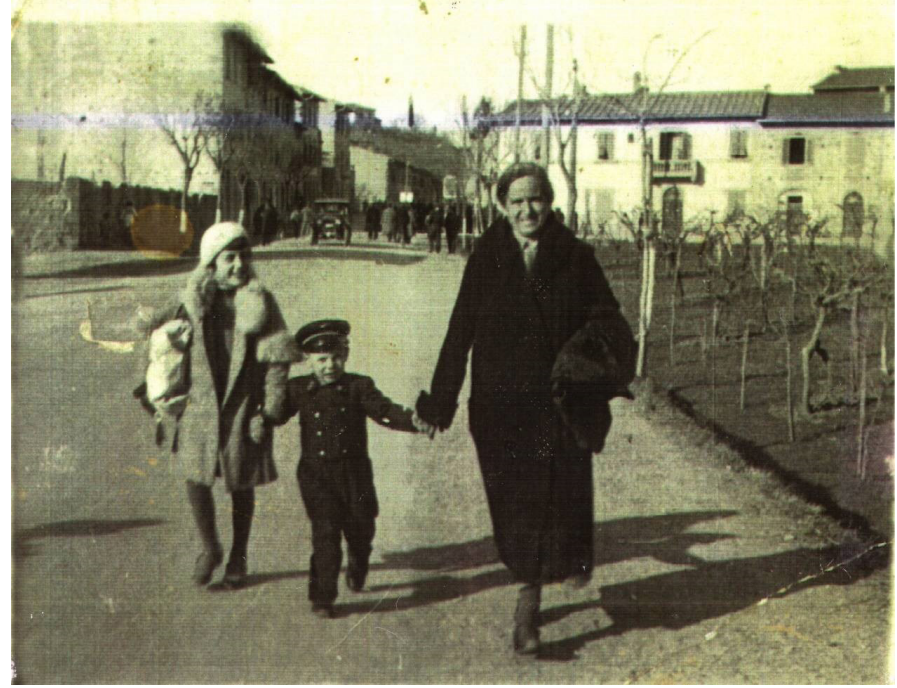

Photo 13. Walking toward the centre — Poggibonsi, 1935

spread and is dispersed into the countryside by deleting their centuries-old relationship.

Until World War II, then, the city had maintained a balance between modern and old: the cities were essentially those bounded by the historic city walls with the presence of some nineteenth century buildings outside the walls and with the rationalism of the period buildings 1920-1940 within the old centre. Until then, in fact, the city identified with what we now call "old towns", harmo-
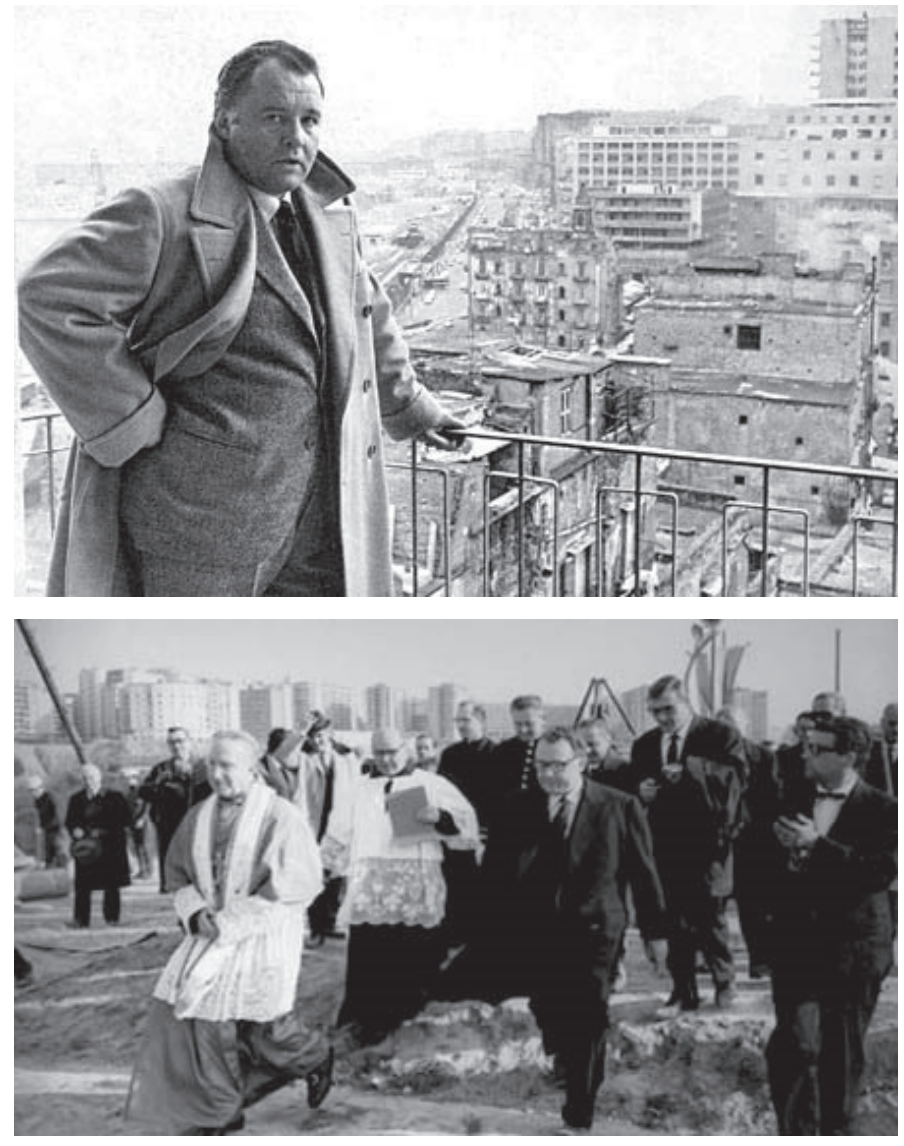

Photos 14-15. Taken from the movie "Le mani sulla città" (The hands over the city) by Francesco Rosi — 1963 nious architectural styles that welcomed the buildings of many different cultural backgrounds, from medieval to the Renaissance, the Baroque, the architecture in the 1800's and art noveau.

With the reconstruction of the post-war period there has been a real upheaval of the social values that accompany the architecture. The national emergency reconstruction, the need for a rapid solution to the housing problem and the economic miracle led to the creation of the suburbs and the new quarters, where they produced more "building amounts" than "urban quality", expanded without limit under the dictates of speculation, regardless of the true and real interests of the community.

This is how the endless anonymous suburbs, well-photographed by the films of Italian neo-realism, which, as Konrad Lorenz said, unroll disorderly building units on the territory defined by lack of connections with the context. The absence of necessary connection created a "loss of information" and the individual component between city and suburb planning therefore plays no role in the general structure and it multiplies uncontrollably. The lack of cultural confrontation led the designers and the entire architectural culture to a period of crisis and lack of identity: the architect who worked only in the suburbs was a kind of exile, during which occurred the impoverishment of the same language. Pier Paolo Pasolini wrote that the suburbs are "boundless places where you believe that the city ends and where it starts again, her enemy, starts again for thousands of times." The negative effects of the monologue, not dialogue are present even today in the lack of tangible openings of the Fine Art Commissions that mostly do not allow the interventions of contemporary architecture in the historic centres regardless of the quality of the project.

The result was that in Italy at the end of the sixties the social characteristics of each part of the city no longer adhered to those functional and morphological relationships, nor to the social ones. The result was the total loss of the historical balance painstakingly achieved over the

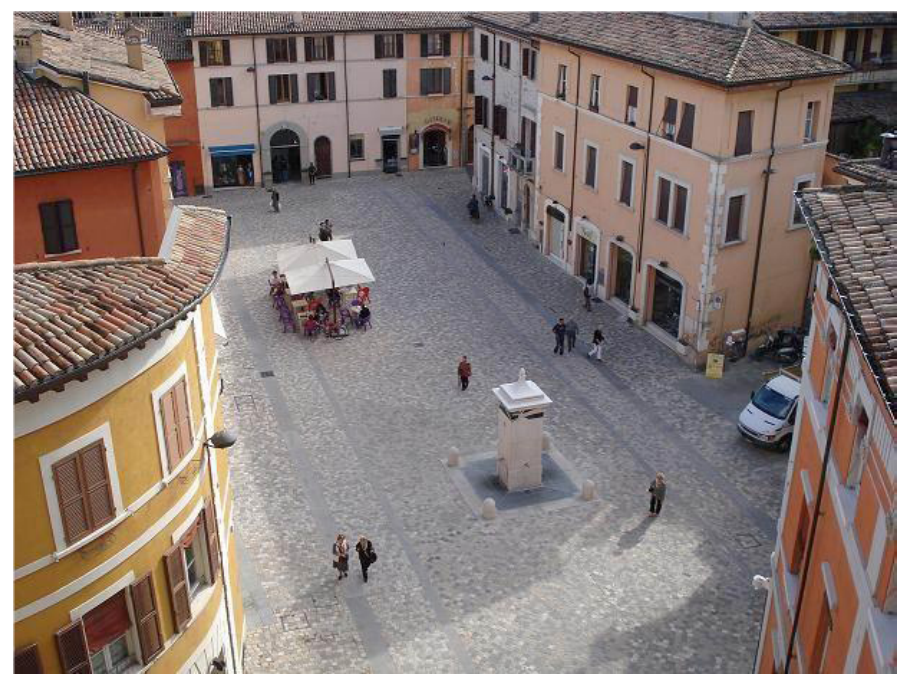

Photo 16. Piazza Amendola, Cesena 
centuries, with the consequent loss of architectural cultural identity that is still being felt. Having built over the last 60 years more than had been built throughout the history of humanity has resulted in preventing the historical sedimentation process that underlies the beauty of the historical centres.

The "project" is the only possible means of control and management of urban transformation and the good project has one of the most decisive and essential in the preservation of historical, artistic and environmental values combined with today's practical needs.

Preservation is transformation and mutation, in the sense that everything flows and everything changes: storage is also mutation, launching a project phase that is responsible and aware of cultural identity. So there is no conservation without innovation.

The protection of historic cities that we have inherited can not be guided exclusively by defending concepts of preservation and urban conservation based on a logical vision of the city, its monuments and museums, but has to be conceived in an organic relationship with the safeguarding of the surroundings.

Renovation and design have always been morally opposed to technological disciplines but in the end the result is the change, as a product of a continuous alternation of elements of continuity and elements of contradiction.

The debate on the modern architrctural project in the historical city

Recovery and innovation are two apparently contradictory terms, but innovation is, first of all, understanding who we are. History and memory are not something abstract, they are what we live and breathe every day: they remain so strong, that people continue to hang around the old centres, huddled up, sacrificed, with a few parking lots, where they have to walk or cycle, but with a big heart, where they continue to hold the markets, festivals and major events.

There is strong relationship between things that surround us: the buildings are like frames of our memories, the roads are like the paths of our memory. For that reason, we would like to leave marks of our passage, traces of our living: this is the meaning of contemporary design.

Abandoning a familiar thought, as a citizen of the path, we feel disoriented. We find ourselves only when also that building, or that shadow projected on the already crowded plaza brings backs our sense of familiarity, stability and protection. So we move on the surface, accustoming ourselves to consider things fixed and stable as we entrust our memory and hope that everything remains stable over time. It is repeating of this process that builds and fixes our memory, day after day, brick by brick, constructing our past.

On the facades plastered with invisible memories, personal memory is linked to the social memory, in a daily space populated by buildings masked by their facades. We find the imprint of an impression passed, as we imagine stepping on the footprint of the steps that we did. Let us rediscover our experience: recognizing the busiest places in our daily lives; rehearsing every day on the way home or to the place that, one hour, one day, a year or a lifetime ago, we had already reached; retracing a path that we believe we have already seen. So we can listen to the voice of the most vivid memories, evoked by renewed attention, come back from the silence giving us the valued sense of belonging.

The incessant repetition and routine of our space gestures, and our relationship with things, explains the way in which we exist in the world that guarantee outward stability to our inner restless being; that order which makes an authentic relationship between us and things. So we want to leave marks of our passage, traces of our living space, and we do it by setting up the city with reminders: by erecting monuments to our existential experience; to build, with them, our environment; to build with them anchored to the reassuring solidity of a stable known structure.

This profound union that inextricably links the memory with the visual memory of the places, explains the dismay we feel when a building disappears: as a matter of fact with it vanishes from our history. The unexpected disappearance, the absence of a reference point, generates the impression of vacuum vertigo. Suddenly looking up, there is a piece of sky where before there was something more: part of ourselves is lost in the frustration of expectation projected on a place that has always been there and suddenly is missing.

The collapse ruins many intimate stories, private and collective, and disperses individual and family memories. The unexpected collapse, sudden amnesia, erases history and generates a new physical reality, but unacceptable failures such us oversights, push men to reconstruct to compensate for a loss, not only physical, never in vain, to regain possession of a past stolen by fate or speculation.

Through places, and their evolution, slow metamorphosis, sudden disappearance, they capture the signs of time; the effects, and sometimes the reasons, of their change. In this light, space and time are useful tools to explore the relativity of history and to understand when, how much and in what way manner we have changed. The present remains are the sign of something that has been and is no longer, but they are also a sign of a scar of a past that should be questioned. The reinterpretation of the unique history of each city, told in secular subjects of dimensional and formal rules of the urban fabric, mainly present in the so-called historic quarters they are the foundations of our common memory. These are the places where for generations all citizens, not just the (few) residents, gathered; where the buildings have kept the memory of the people, the community and the multitude of visitors who, even today, find themselves "in the centre."

It often happens that even in the complicated reality of the historical centres, the architect's narcissistic attention moves from the analysis of what is common memory and historical place to self-analysis and self-referentiality (recognition). Similar design intent often leads to considerable exemplary gestures that can enhance an urban reality without strong and centuries-old memories, but it becomes difficult to accept the opposite where for generations man defended its common identity, reflected in the 
beauty and integrity of the city, its walls and its squares. In many degraded historical centres, worn by time, and neglect, there is no need for redesigning; but rather for new architectures that communicate with the old ones. This doesn't necessarily means we do not want to go back to the old styles but we want an architecture that arises from a dialogue between the architect and his most powerful patron: the city, in its broadest sense.

However, in recent years there has been a serious search for new parameters to guide the future of architectural design. The responsibility to express the modern sense of our age produces the awareness to stay connected to the tradition, by injecting the best technological resources into the existing urban fabric and giving an architectural form of the highest quality to new buildings. Just so we can restore life and identity to the city.

Therefore, there is no need to debate which architecture is right or wrong, if the modern is bad or if the old is beautiful but we have that the city, to greet and accept the newly-fashioned buildings and allow time to blend them with pre-existing context, as was always done, and will continue to contribute to the development of his vital environment.

\section{city}

The modern architectural project in the historic

The fabric of the city is vital, pulsing, paradoxically to "keep" means just to "modify" and then we have to redesign the existing updating it in accordance with its historical essence.
The city has always been characterized by emerging buildings (monuments) and by the standard building: in the perfection of this harmony lies the true secret of urban beauty. You should therefore not be afraid to create new architectural emergencies because it might disrupt this natural harmony, but we must promote the concept of continuity, that is, the mutation of the order of a tradition.

The architect, when he approaches the design theme, is always involved in the debate "traditio" and "innovatio" which always coexist in time.

Every city develops it own 'genius loci', the sense of belonging, the desire to live in one particular city that one wishes to ultimately call home.

It is the childhood neighborhood with its secrets, its friendly space, warm, secure, it is home.

The path of the architect to reach the good project of modern architecture in historical cities can be expressed in three different layers:

1. the information layer

2. the interpretation layer

3. the creative layer

In each phase the architect has to work on the old building or historical centre using his own skills: so the good project is the perfect combination of these two components.

This approach can lead to different final results, according to the building or area's features and the architect's sensibility.

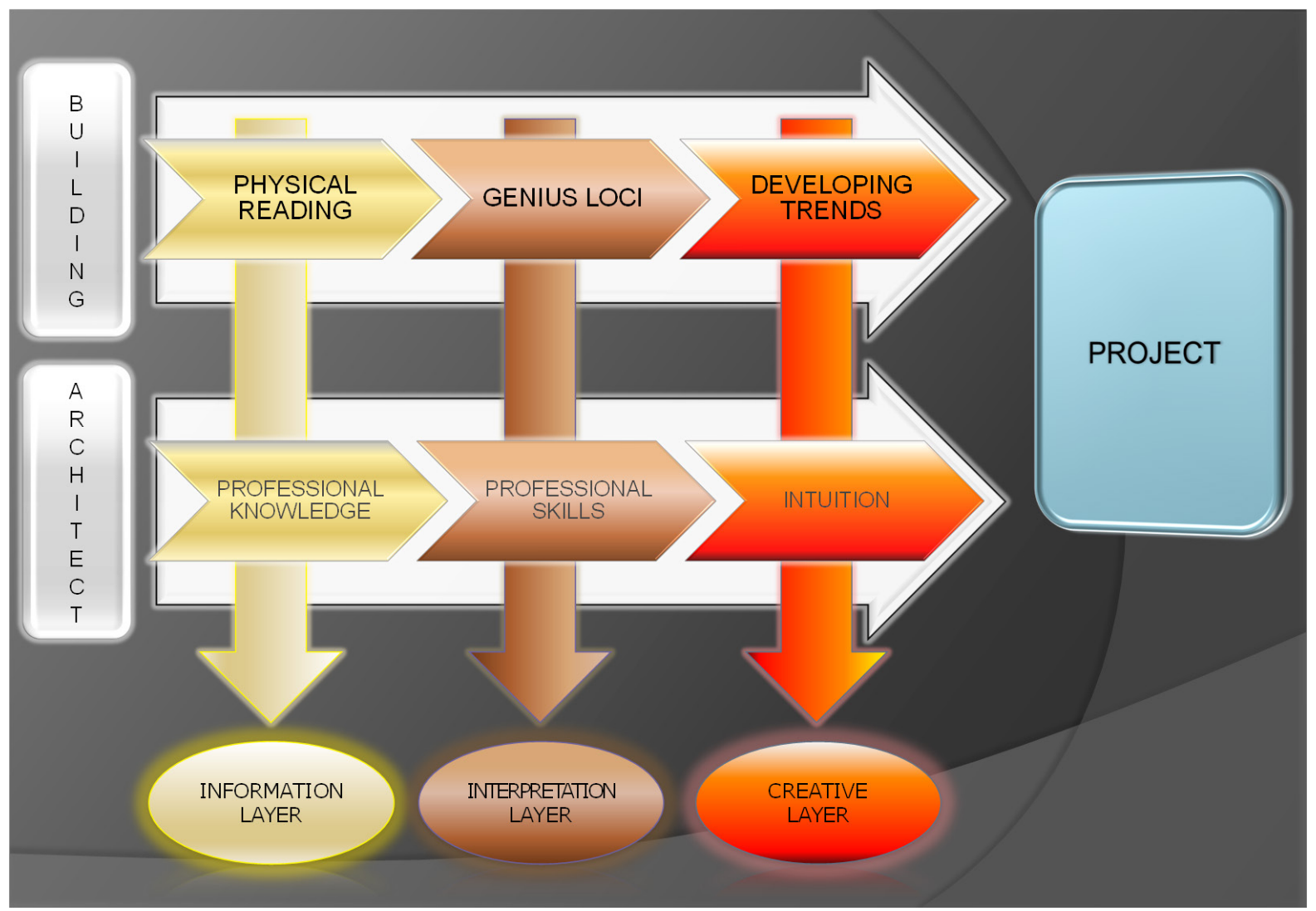




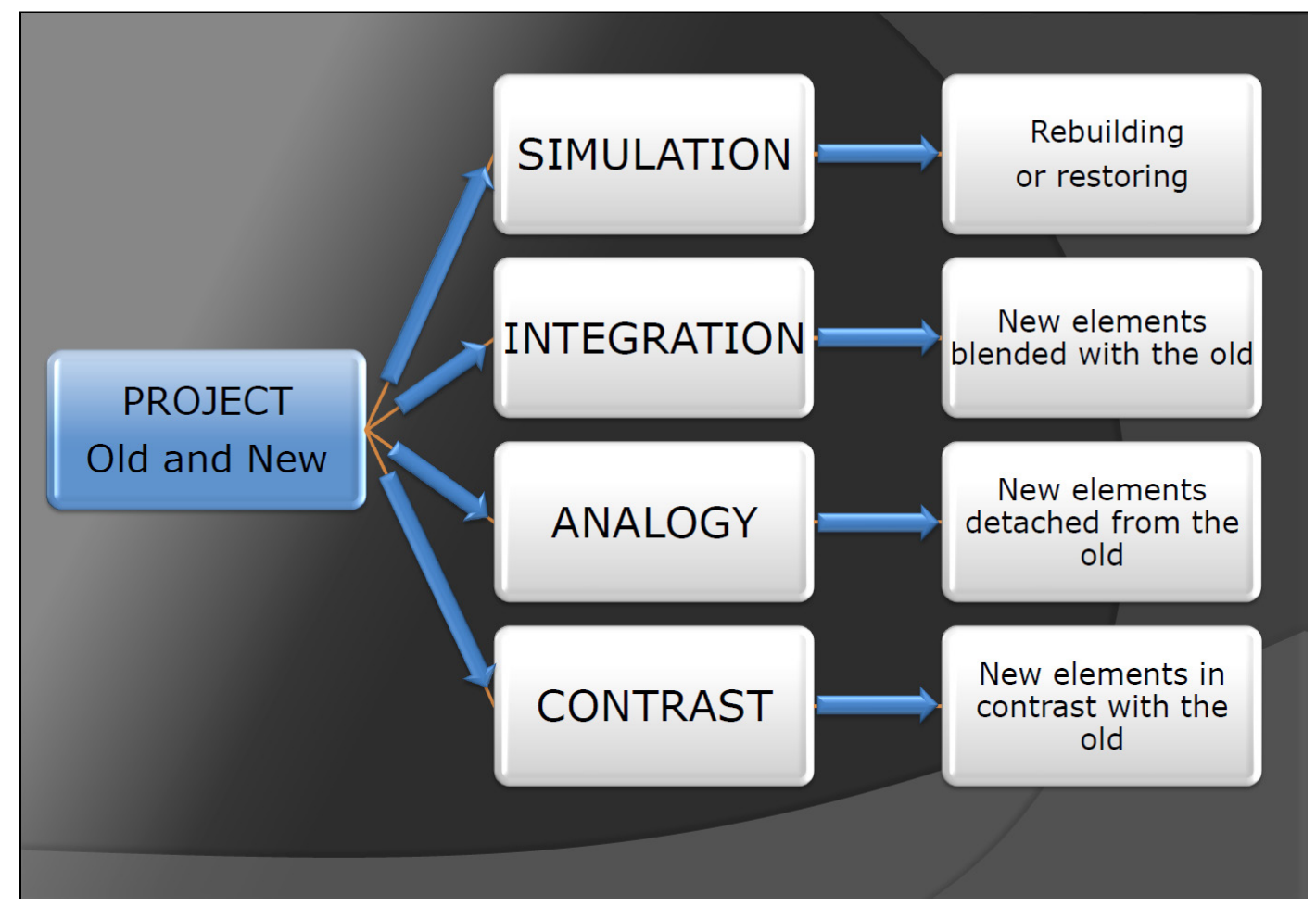

\section{Simulation examples}

They faithfully reconstruct the existing order to strictly respect the technical and cultural integrity, enhancing the essence.
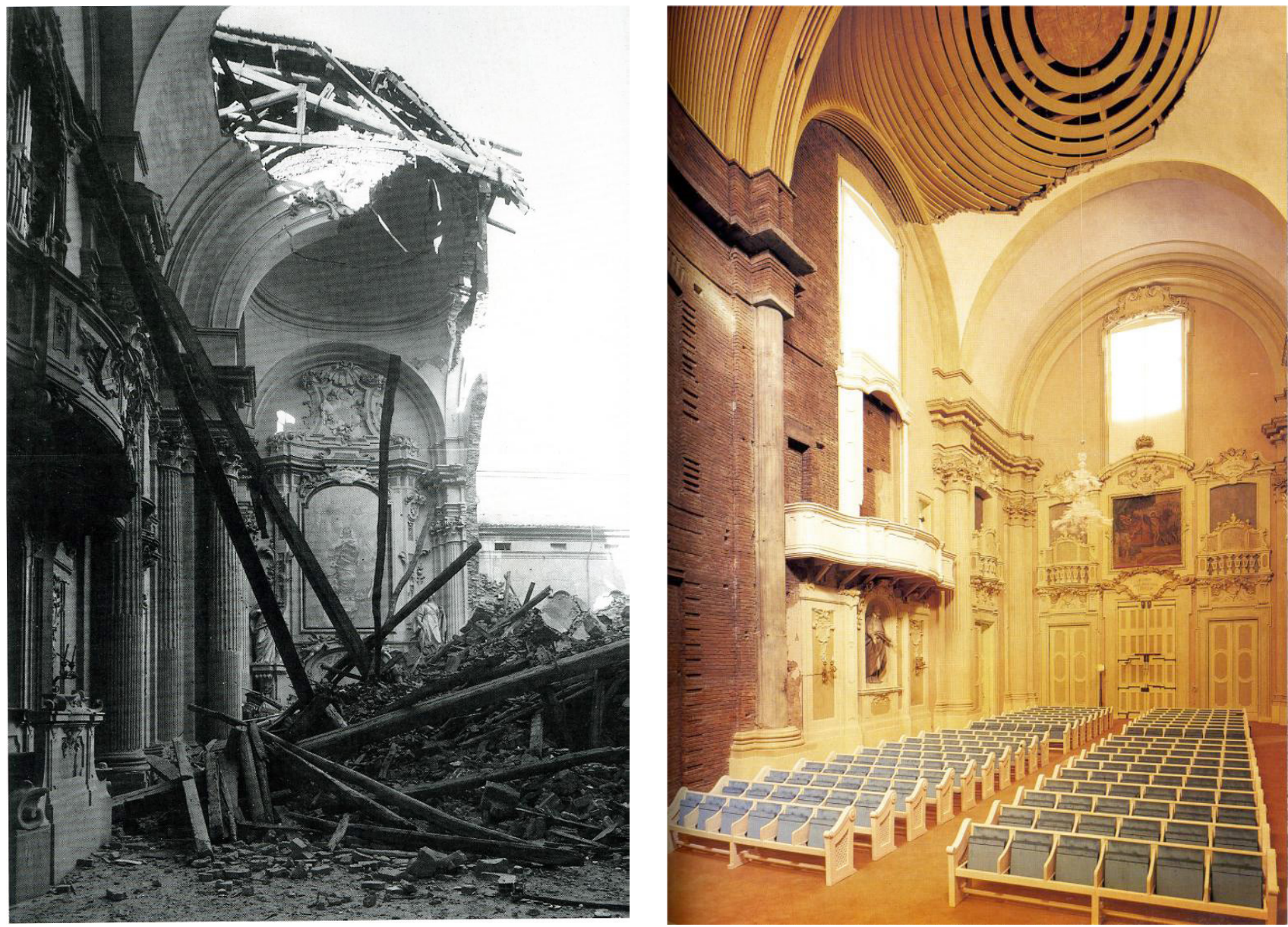

Photos 17-18. SIMULATION EXAMPLE: San Filippo Neri oratory, Bologna, Arch. P. Cervellati, 1997 


\section{Architecture and Engineering Volume 1 Issue 2}

\section{Integration Examples}

They express the overcoming of reverence for the old and insert new elements closely aligned with those historians in full continuity with the old.

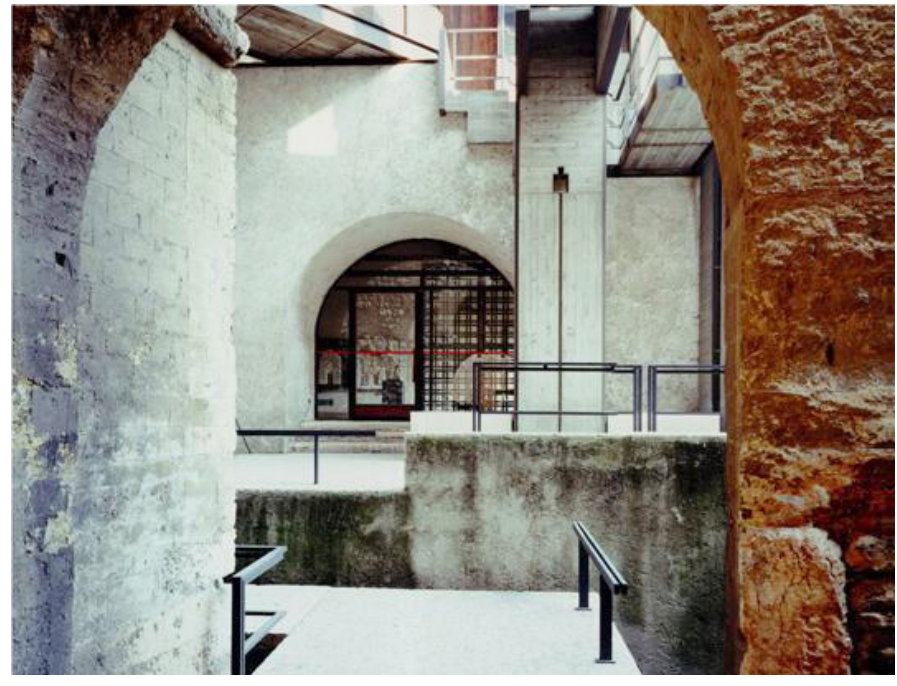

Photo 19. INTEGRATION EXAMPLES: Castelvecchio museum, Venezia, Arch. C. Scarpa

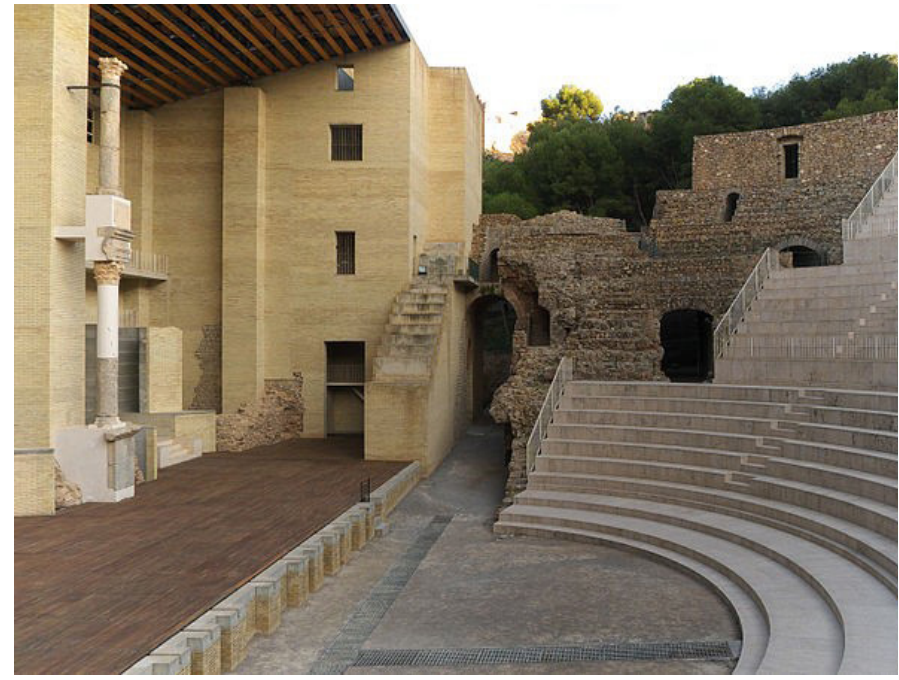

Photo 20. Roman Theatre, Sagunto, Arch. G. Grassi

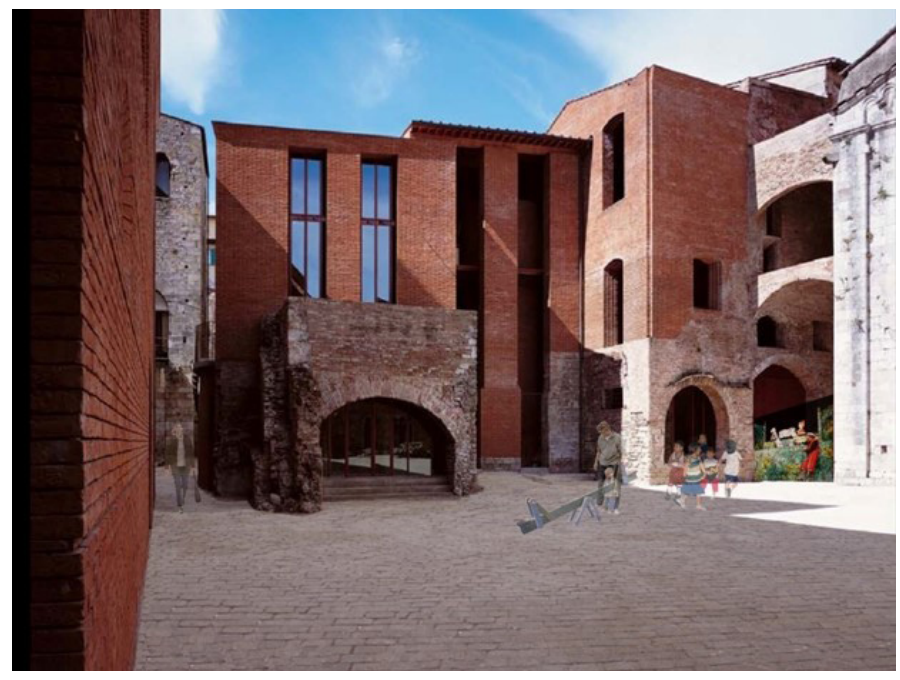

Photo 21-22. INTEGRATION EXAMPLE: San Michele Old village, Pisa, Arch.M. Carmassi
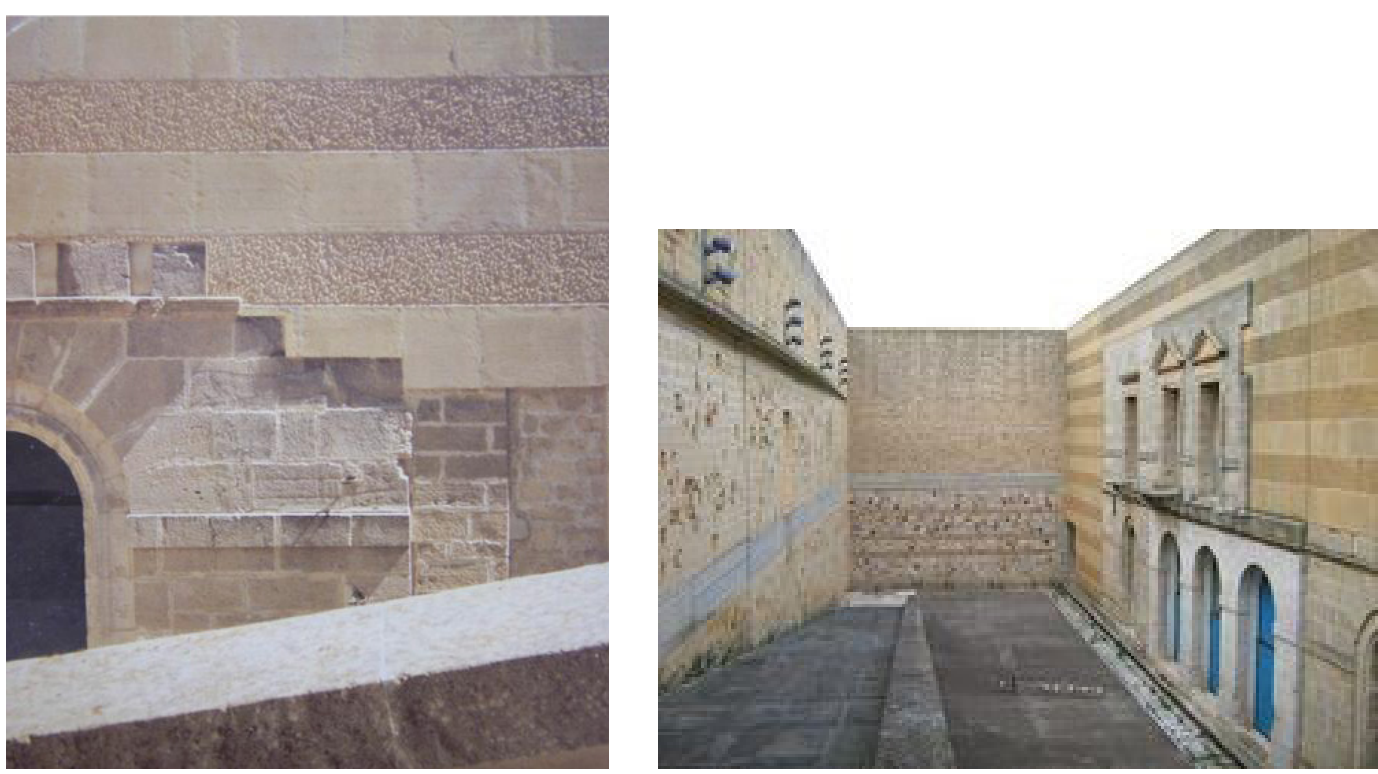

Photo 23-24. INTEGRATION EXAMPLE: San Michele Old village, Pisa, Arch.M. Carmass 

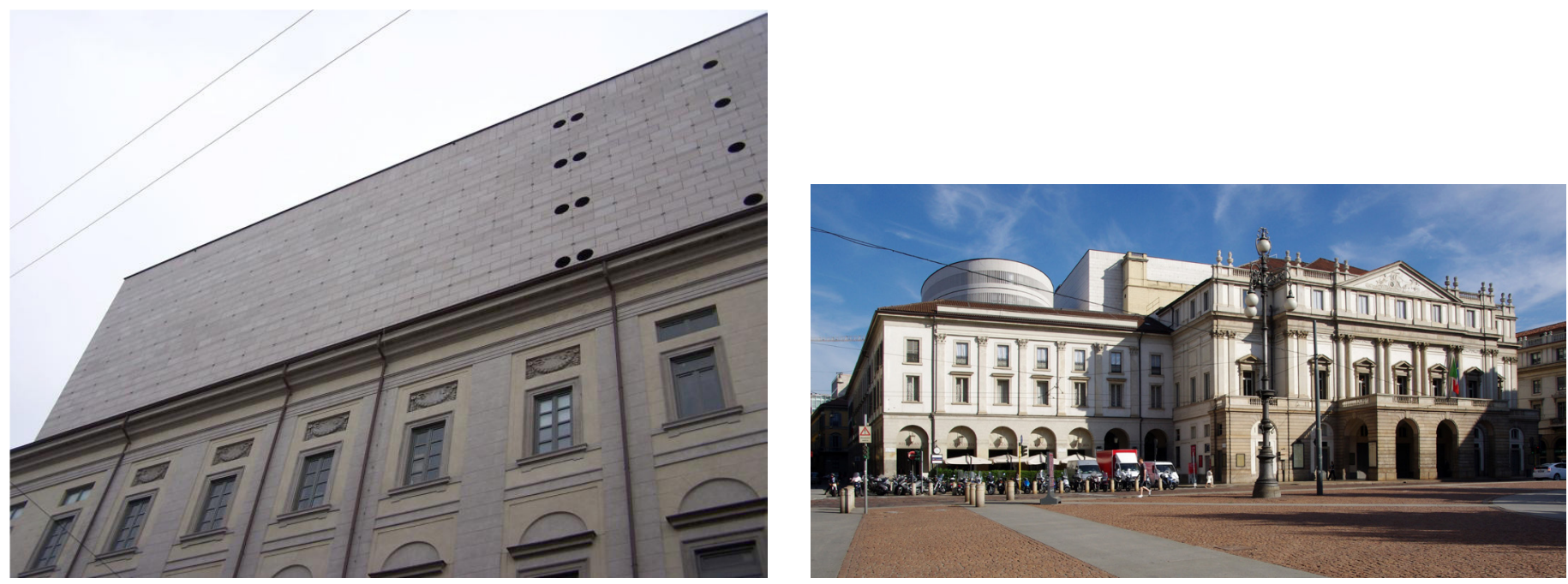

Photo 25-26. INTEGRATION EXAMPLE: Teatro della Scala rebuilding, Milano, Arch. M.Botta
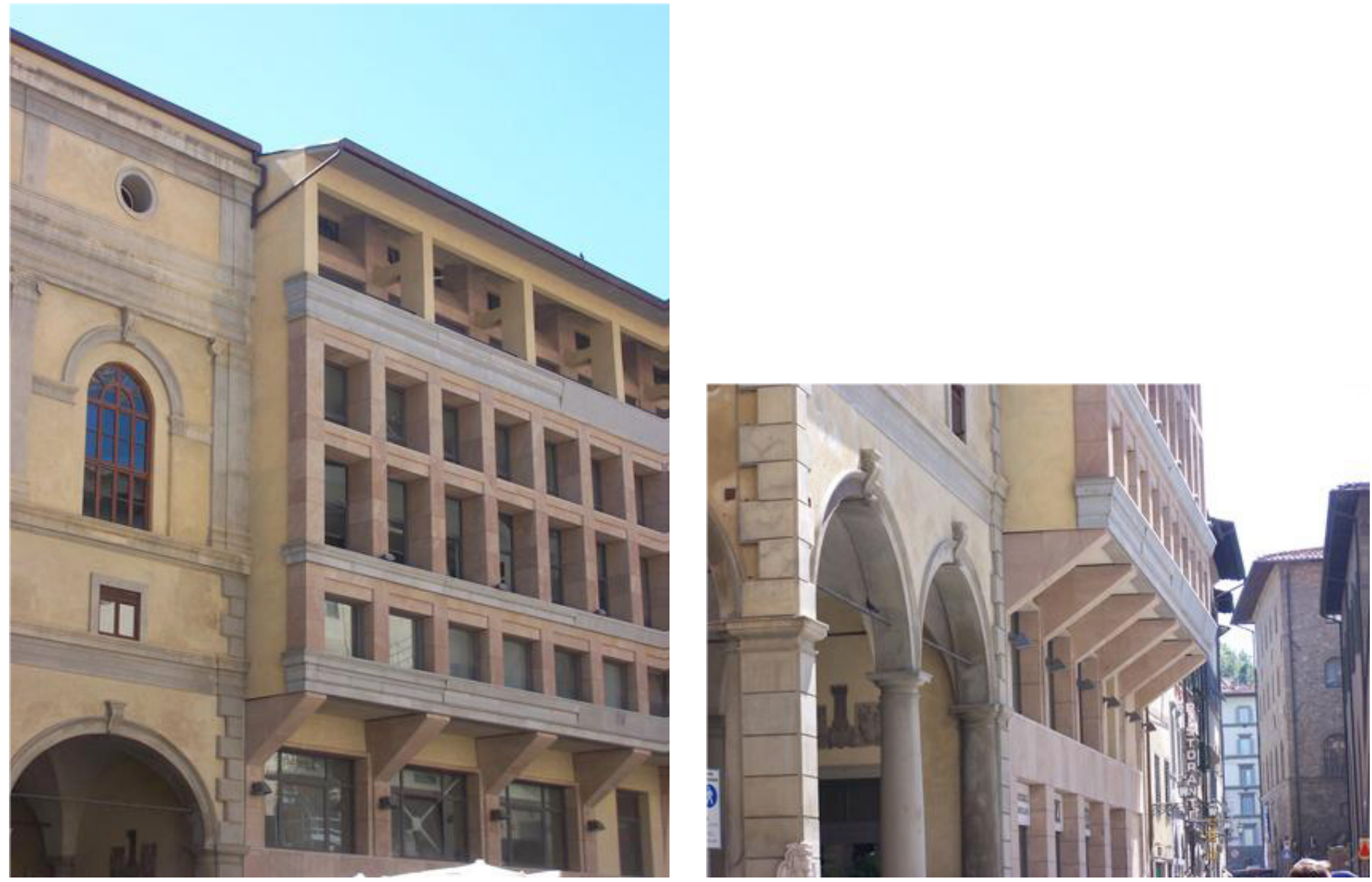

Photos 27-28. INTEGRATION EXAMPLE: Uffizi Center, Firenze, Arch. A. Natalini 


\section{Architecture and Engineering Volume 1 Issue 2}

\section{Analogy examples}

They reopen a dialogue with the pre-existence, interrogating and interpreting and exalting its best characters with the insertion of innovative elements and architectures, separated physically from those ancient.
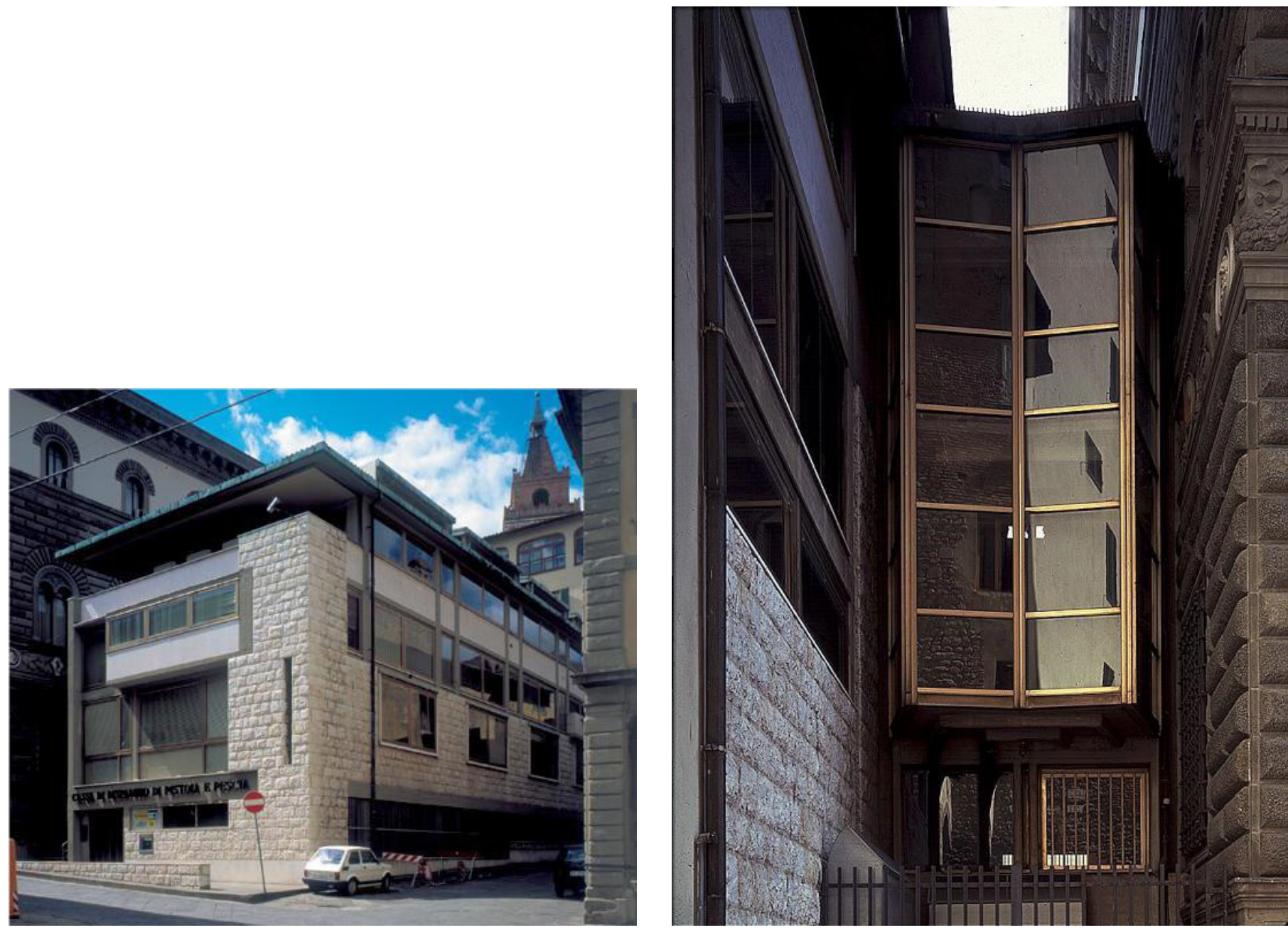

Photo 29-30. ANALOGY EXAMPLE: La Borsa Merci, Pistoia, Arch. G.Michelucci, 1950

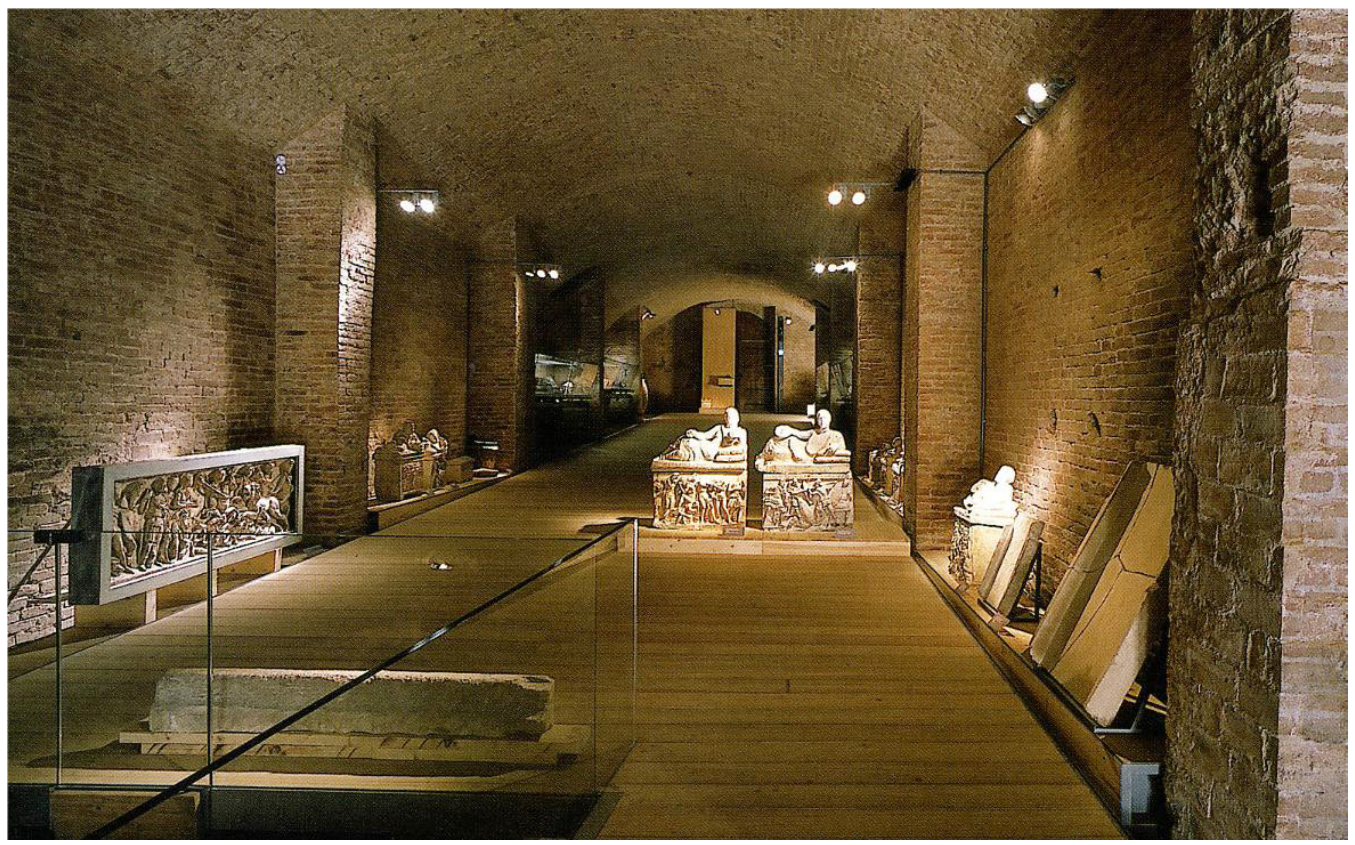

Photo 31. ANALOGY EXAMPLE: Santa Maria della Scala Museum, Siena, Arch. G.Canali 

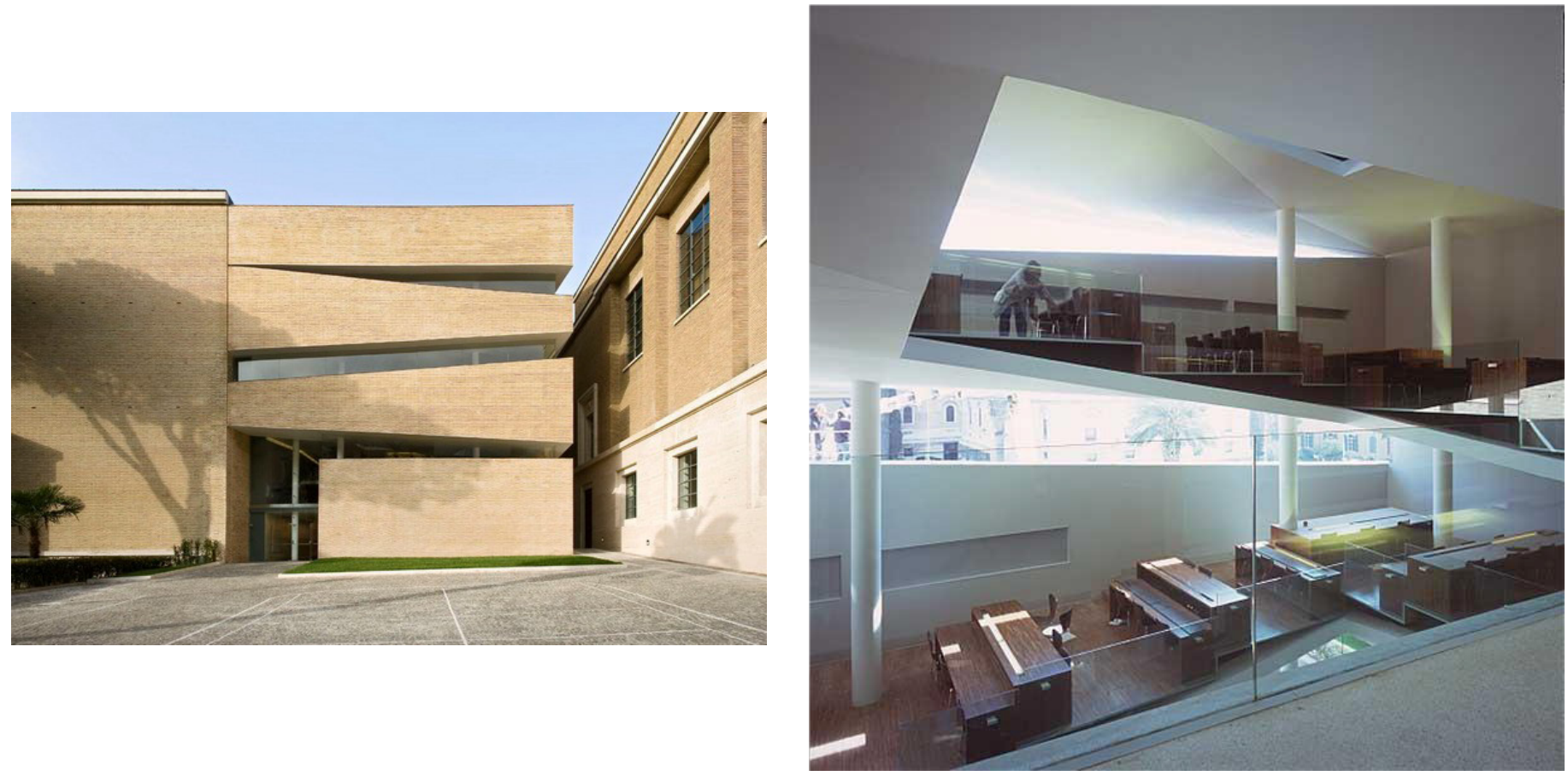

Photos 32-33. ANALOGY EXAMPLE: Aula Magna dell'Università Pontificia Lateranense, San Pietro, Roma, studio King Rosselli
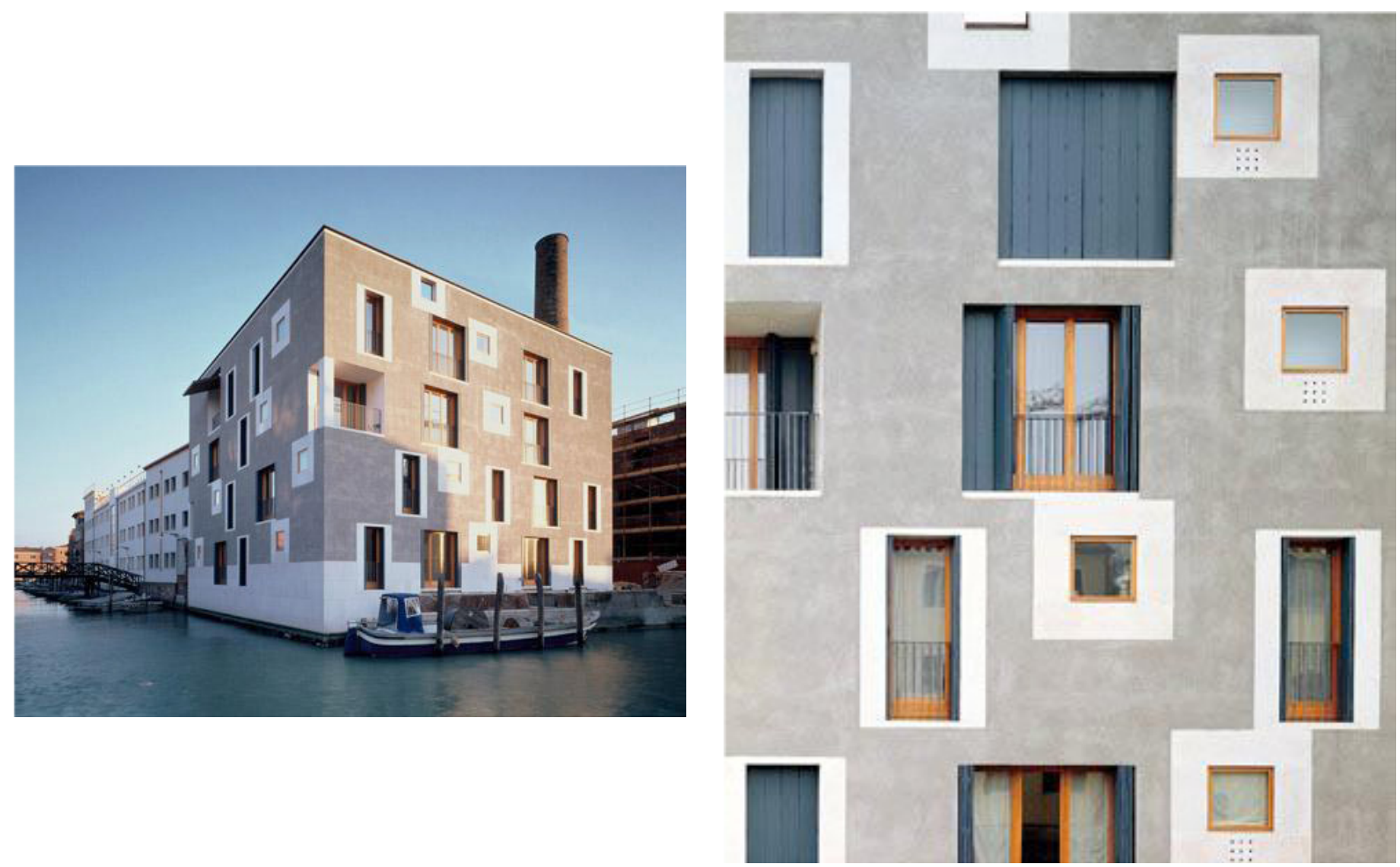

Photos 34-35. ANALOGY EXAMPLE: Nuove residenze, Venezia, Arch. C. Zucchi, 2002 


\section{Contrast examples}

They mark a contrast to enforce the new alongside the old and then highlight two specific cultural identities: the new materials and architectures are realized with a wise respect for the contest which emphasize the beauty of the differences.

"The steel structure will not touch any point of the original walls. The thread of my restoration projects has always been the insertion of modern architecture into a pre-existing space without creating any confusion. For this reason I choose steel, which is diametrically opposed to bricks of the original building. The restoration must be shown even in respect to the historic structure."

Giancarlo De Carlo (1919-2015) Italian architect
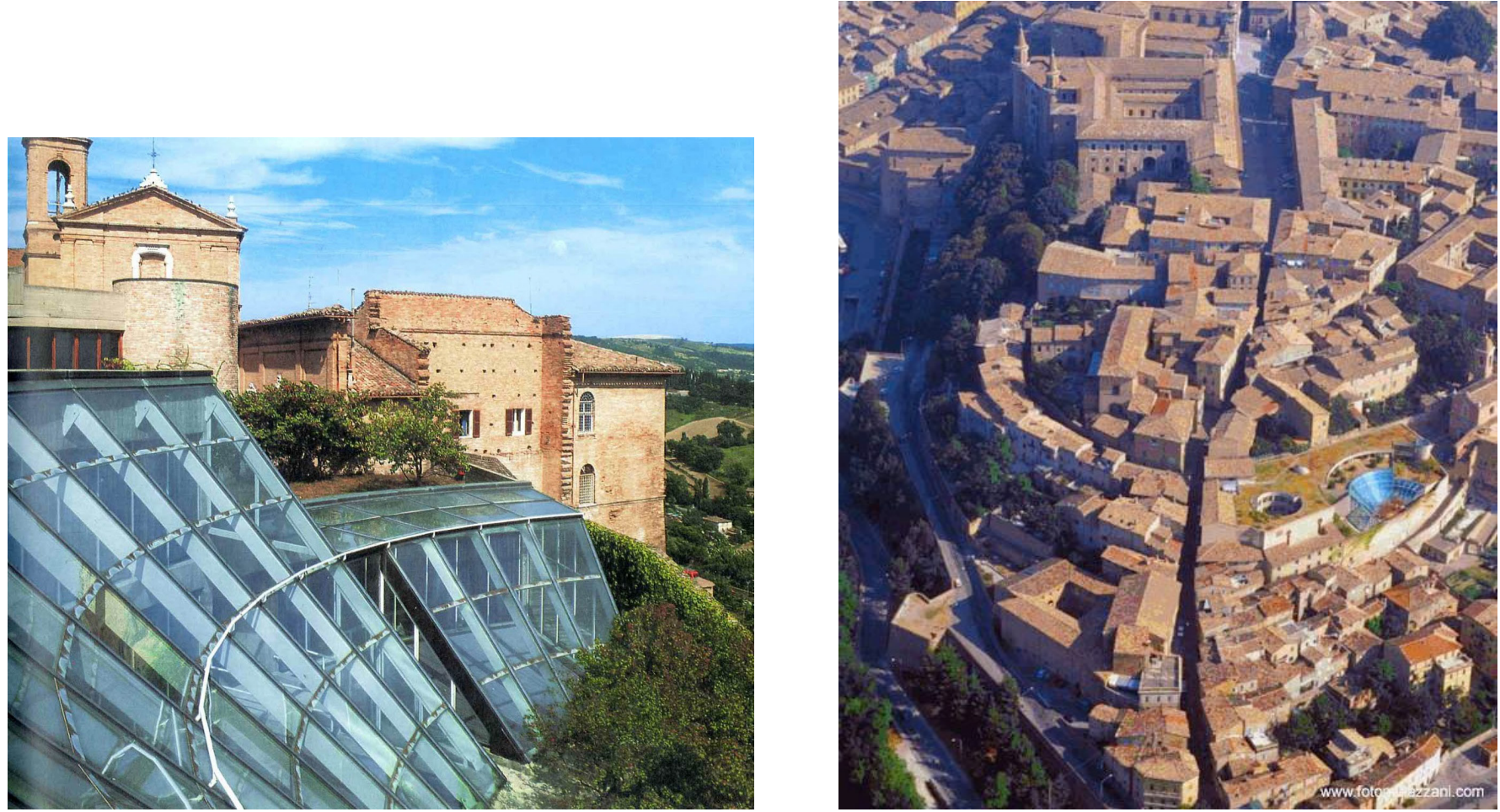

Photos 36-37. CONTRAST EXAMPLE: University of Urbino: Faculty of Education, Urbino, Arch. Giancarlo De Carlo
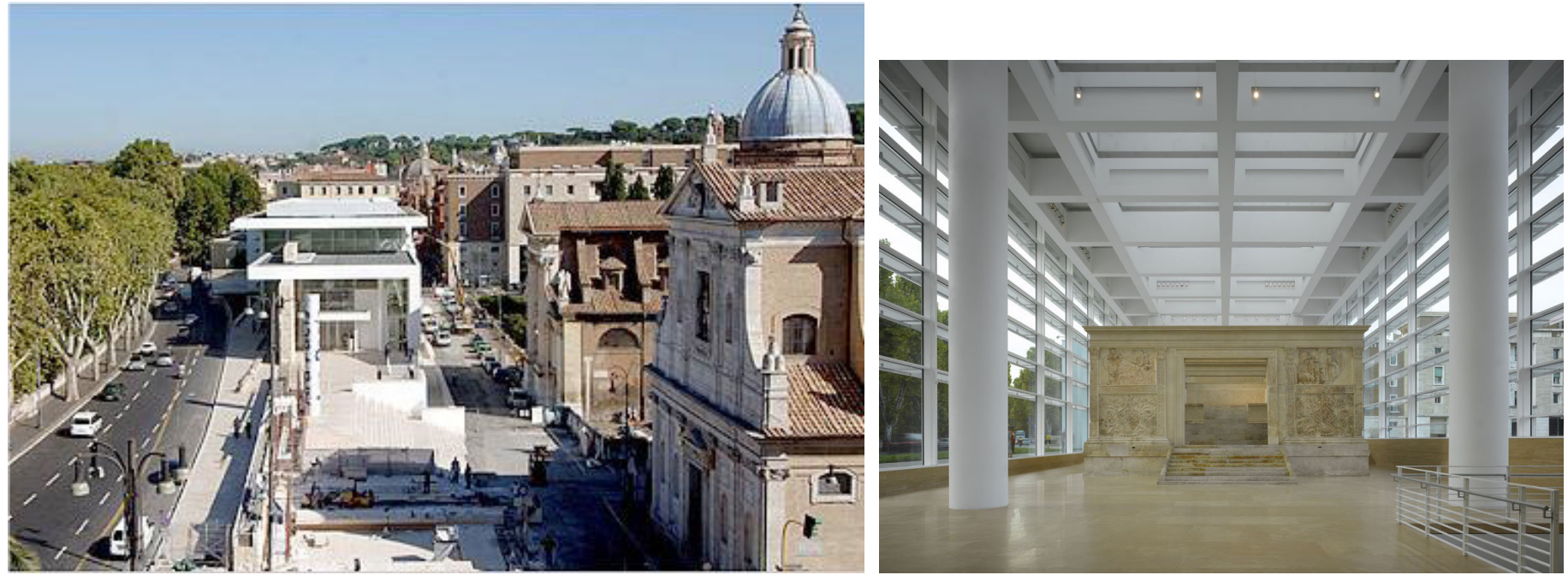

Photos 38-39. CONTRAST EXAMPLE: Ara Pacis museum, Roma, Arch. R. Meier \& Partners 

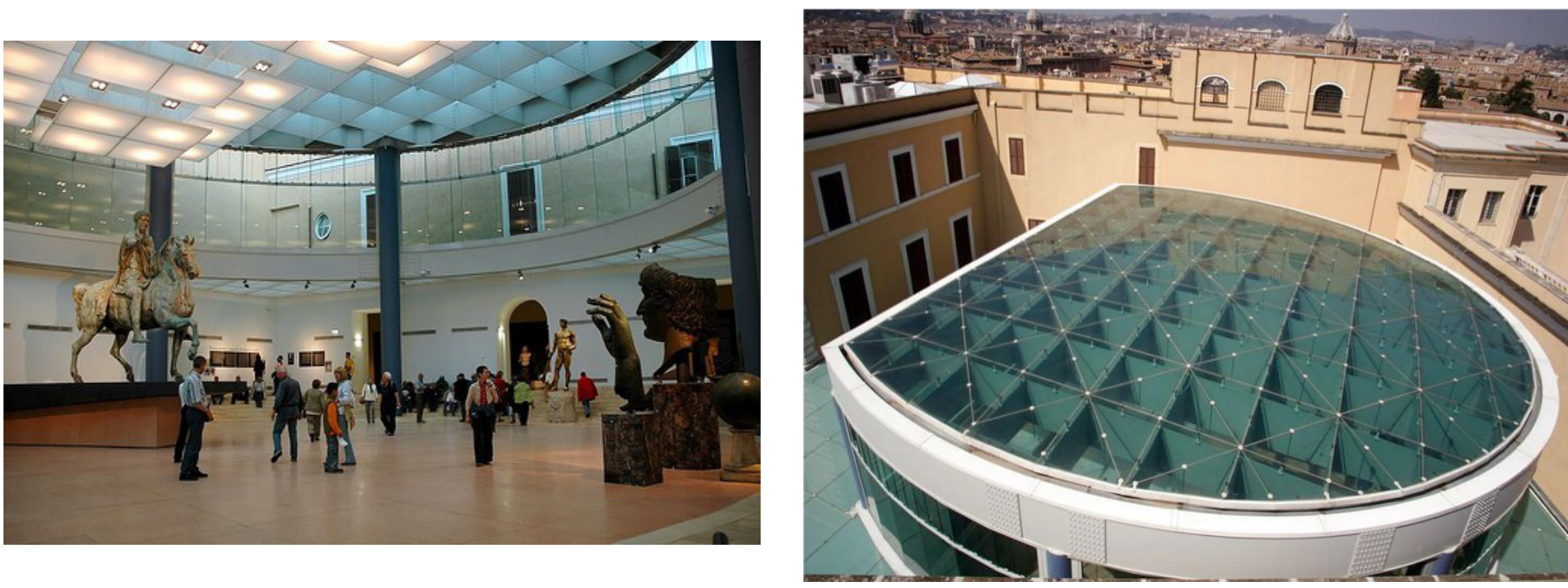

Photo 40-41. CONTRAST EXAMPLE: Campidoglio museum, Roma, Arch. C. Aymonino

\section{Some thoughts from famous Italian architects}

"The past does not exist. Everything in our culture is simultaneous. Only the present exists in the interpretation that we make of the past and in the view we have of the future."

Giò Ponti (1891-1997)

"Architecture is the notary of history."

Giuseppe Pagano (1896-1945)

"The quality of a project depends on the degree, even minimal, of the cultural exchange that is sparked by it."

Enzo Mari (1932)

"The best architect of the city is time."

Renzo Piano (1937)

"Everyone fears novelty. Novelty is seen as something insidious without realizing that everything that is protected so vehemently was once novelty."

Francesco Venezia (1944)

\section{Conclusion}

There isn't a unique recipe for design in the old town, but there are several trends that often influence each and contaminate each other, exploring new trails from the point of view of composition. Preserving the past needs a project that gives life where the new must find a way with the old.

Architecture is the relationship between space, actions and human behaviour: it defines organizations, centrality, proximity, continuity, discontinuity, filters, routes, mediation, expansion and spatial compressions.

It intersects the contexts of which it will become part: it transforms, innovates and consolidates the logical topological principles and the context into which it plunges.

There are two main principles:

1 - it is not correct to think the city is made up of distinct parts, each part is a fragment of a whole, of the urban and territorial system, the environment, the landscape, the memory layers, as a whole coming together as a whole

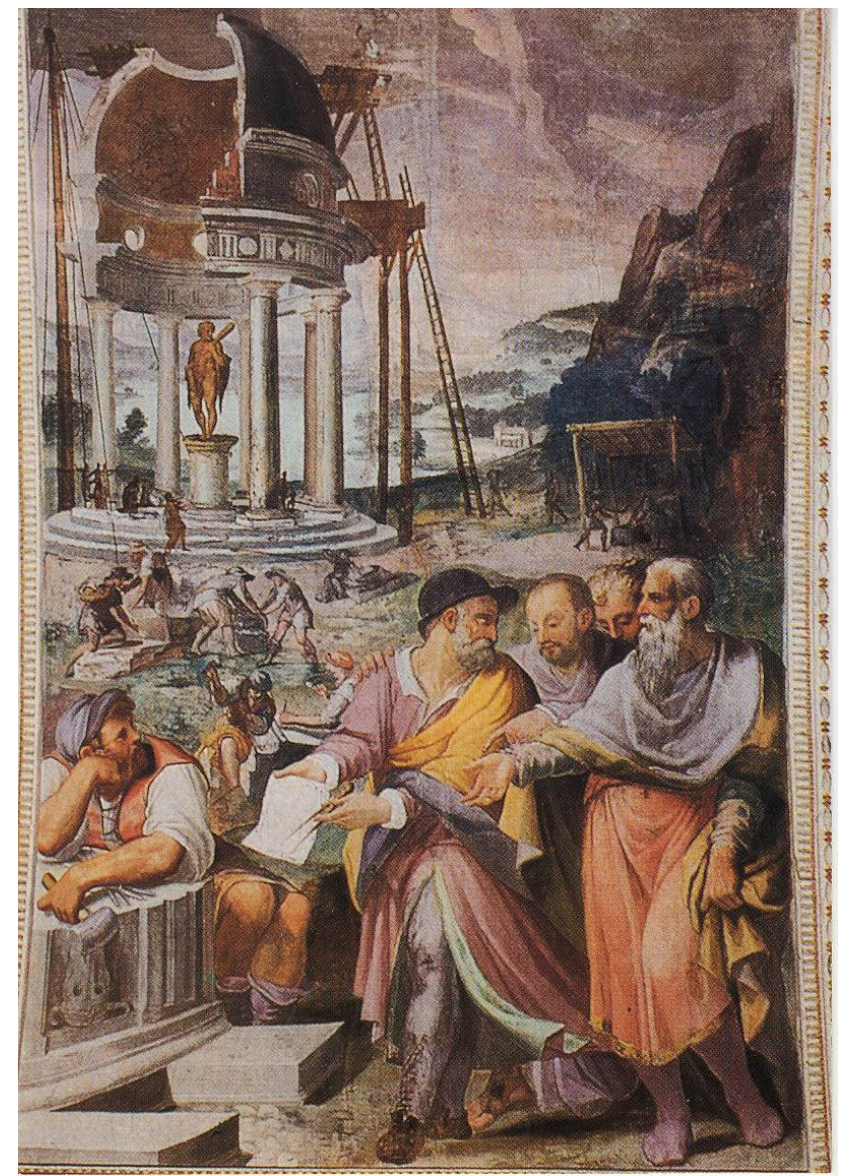

Photo 42. Fresco in the Farnese Palace, Caprarola, showing Arch. Jacopo Barozzi detto II Vignola, in a building site meeting, 1569

but made up of the individual aspect and characteristics of each part.

2 - it is substantial understanding of the urban space, simultaneously, in its physical and spatial character and feeling the city as a continuous transformation, a place of meetings, exchanges and sharing.

The true lesson of tradition is therefore not only about restoration, but also about change and innovation. 


\section{Architecture and Engineering Volume 1 Issue 2}

\section{References}

Giovannoni G (1944) II dopoguerra dei monumenti e delle vecchie città italiane. In «Nuova Antologia».

Michelucci G (1954) Le ragioni di una polemica. In «La Nuova Città», n. 14-15.

Pane R (1956) Città antiche edilizia nuova. Relazione al Conegno INU di Torino, Italy.

Jung CG (1957) Presente e futuro. Bollati Boringhieri, Torino, Italy.

Pane R (1957) Restauro dei monumenti e conservazione dell'ambiente antico in Attualità e urbanistica del monumento e dell'ambiente antico. Atti del Convegno Milano.

Tentori F., Note sul Convegno dell'I.N.U., VI Convegno nazionale di Urbanistica; appendice a «Casabella-Continuità», n. 217, 1957 e «Urbanistica», n. 23 - 1958.

Bottoni P (1963) Problemi della moderna composizione architettonica negli ambienti storici e nel restauro dei monumenti. Milano, Italy.

Bardeschi Dezzi M (1982) La materia e il tempo, ovvero: la permanenza e la mutazione. In «Recuperare», n. 2.

Tafuri M. (1944-1985) Storia dell'architettura italiana.

Miarelli Mariani G (1987) La città storica: alcuni nodi del recupero. In "Anastilosi”, L'antico, il restauro, la città, a cura di F. Perego. Bari, Italy.

Carbonara G (1990) Restauro tra conservazione e ripristino. In "Palladio".

Blasi C (1991) Progettazione imitativa e progettazione generativa: due modelli in conflitto. In "A-Letheia", Alinea, n. 2.

Todorov T (1995) Le morali della storia. Einaudi.

Carbonara G (1996) Teoria e metodi di restauro. Utet.

De Carlo G (2005) La visibilità dell'architettura contemporanea. In «Domus», 882.

Intervista a Pica Ciamarra M., Temi antichi per la città contemporanea, linguaggi nuovi nella città storica — 2005.

Intervista a Luigi Prestinenza Puglisi - 2005.

Zuffi V (2005) Ri-costruire nei centri storici.

Benevolo L (2006) Una città con tanti centri. In "Italia Nostra".

De Pascalis G (2006) Da periferia a città — intervista a Pier Luigi Cervellati. In "Italia Nostra”, n. 416.

Bardeschi Dezzi M (2007) Cultura e qualità del progetto contemporaneo nella città esistente. Convegno di Studi. Gubbio, Itlay. Clarelli M (2008) Architettura contemporanea in contesti storici italiani.

Ricca L (2010) Atti del convegno italo-giapponese - Un confronto sulle città storiche: conservazione e trasformazione.

Atti del convegno, Si può costruire nei centri storici? Arezzo, Italy.

Carbonara G (2011) Architettura d'oggi e restauro. Un confronto antico-nuovo. 